UNIVERSIDADE DE SÃO PAULO

FACULDADE DE ODONTOLOGIA DE BAURU

MARCELO SALMAZO CASTRO

Impacto da pandemia de SARS-CoV-2 (COVID-19) na saúde emocional e na Síndrome de Burnout em cirurgiões-dentistas no Brasil

BAURU 



\section{Impacto da pandemia de SARS-CoV-2 (COVID-19) na saúde emocional e na Síndrome de Burnout em cirurgiões-dentistas no Brasil}

Dissertação constituída por artigo apresentada à Faculdade de Odontologia de Bauru da Universidade de São Pulo para obtenção do título de Mestre em Ciências no Programa de Ciências Odontológicas Aplicadas, na área de concentração Saúde Coletiva.

Orientador: Profa. Dra. Silvia Helena de Carvalho Sales-Peres

\section{Versão Corrigida}

BAURU 
Castro, Marcelo Salmazo

Impacto da pandemia de SARS-CoV-2 (COVID-19) na saúde emocional e na Síndrome de Burnout, em cirurgiões-dentistas no Brasil / MARCELO SALMAZO CASTRO- Bauru, 2021.

85p.: il.; $31 \mathrm{~cm}$.

Dissertação (Mestrado) - Faculdade de Odontologia de Bauru. Universidade de São Paulo

Orientadora: Profa. Dra. Silvia Helena de Carvalho Sales-Peres

Nota: A versão original desta dissertação/tese encontra-se disponível no Serviço de Biblioteca e Documentação da Faculdade de Odontologia de Bauru - FOB/USP.

Autorizo, exclusivamente para fins acadêmicos e científicos, a reprodução total ou parcial desta dissertação/tese, por processos fotocopiadores e outros meios eletrônicos.

Assinatura:

Data:

Comitê de Ética da FOB-USP

Protocolo $\mathrm{n}^{\mathrm{o}}: 4.239 .328$

DATA: $26 / 08 / 2020$ 
ERRATA 

FOLHA DE APROVAÇÃO 



\section{DEDICATÓRIA}

Dedico essa dissertação a minha família, pilar fundamental da minha vida.

Aos meus pais, Maria Salete Salmazo Castro e Ailton de Oliveira Castro (in memorian), que me deram os alicerces educacionais e morais, valores estes que me proporcionam poder percorrer todo o meu caminho profissional. Pai, sei que apesar da sua ausência física, você esteve sempre ao meu lado, me protegendo, me orientado e me mostrando o caminho certo a ser trilhado. Sei que você gostaria de estar aqui ao nosso lado para podermos nos abraçarmos, mas saiba que em nenhum momento vou esquecer tudo o que você fez por mim. Obrigado por tudo e beijos de luz, Te Amo. À minha irmã Isabela, também cirurgiãdentista, que me deu o suporte clínico nas minhas ausências.

À minha amada esposa Natália Mariana Frari Castro, meu porto seguro, guerreira, companheira, conselheira, extremamente amorosa e incentivadora do meu trabalho. Não tenho palavras para agradecer todo seu apoio para a conclusão do meu trabalho. Obrigado amor!

À minha filha Gabriela Frari Castro, a fonte das minhas inspirações e forças para enfrentar qualquer adversidade.

À Deus que me permitiu encontrar pessoas tão especiais no meu caminho e a todas as suas bênçãos e a sua proteção.

À Nossa Senhora, mãe de Nosso Senhor Jesus Cristo, que sempre me cobriu com seu manto protetor, me guiando e me protegendo de todos os males. 



\section{AGRADECIMENTOS ESPECIAIS}

Agradeço imensamente à minha orientadora Profa. Dra. Silvia Helena de Carvalho Sales-Peres pela forma humana que me acolheu, ensinou e conduziu o meu trabalho. Sua garra, determinação, amor pela profissão e conhecimentos foram fundamentais para a conclusão deste trabalho. Vou levá-la para sempre em meu coração e orações. Muito obrigado!

Agradeço imensamente a todos os profissionais que se dispuseram a responder $\mathrm{o}$ questionário que foi o instrumento de trabalho deste estudo. Gratidão!

Agradeço à funcionária do Departamento de Saúde Coletiva, Silvia Cristina Tonin Costa, e da Clínica de Pós-Graduação, Hebe Freitas, pelo carinho, ajuda, suporte e compreensão.

Agradeço ao Prof. Dr. Arnaldo Pinzan e Profa. Dra. Juliana Fraga Soares Bombonatti por terem aceitado participar da minha banca de qualificação do mestrado e terem contribuído de forma ímpar para a melhoria deste trabalho com seus ensinamentos e experiência.

Agradeço ao Prof. Dr. Eliel Soares Orenha que me orientou durante as clínicas de Saúde Coletiva.

Agradeço aos amigos da Pós-Gradução: Ana Carolina Silva Pinto, Bruno Lugerio, Fabiano Aznar, Genesis Domenici Merejo, Gérson Ap. Foratori-Junior, Jefry Vargas, Rogério Bertevello e Sabrina M. Rufino Moreno por toda ajuda, companheirismo, paciência, orientações e trabalho de equipe.

Agradeço a minha colega Ana Virginia Sampaio Castilho que por muitas vezes me orientou e me deu força durante a minha caminhado no mestrado.

Agradeço a Ellen Gomes por todo apoio no meu início do mestrado.

Agradeço a meu amigo de graduação Rogério Eleutério Abdalla por todo apoio durante a elaboração do meu trabalho. 



\section{AGRADECIMENTOS INSTITUCIONAIS}

O presente trabalho foi realizado com o apoio da Coordenação de Aperfeiçoamento de Pessoal de Nível Superior - Brasil (CAPES) - Código de Financiamento 001.

Agradeço a Faculdade de Odontologia de Araraquara - Universidade Estadual Paulista, e a todos os professores desta instituição que foi a responsável pela minha formação de graduação da odontologia.

Agradeço à Faculdade de Odontologia de Bauru - Universidade de São Paulo, representada pelo excelentíssimo Diretor Prof. Dr. Carlos Ferreira dos Santos, por ter me proporcionado todas as condições para desenvolver meu trabalho. 

"A persistência é o caminho do êxito." Charles Chaplin 



\section{RESUMO}

A contaminação causada pelo vírus SARS-CoV-2 coloca o cirurgião-dentista no topo do risco de infecção. Entretanto, os profissionais necessitam continuar realizando o trabalho odontológico, sendo expostos aos riscos de contaminação. Dessa forma, o presente estudo teve por objetivo primário avaliar a presença ou não da SB nos cirurgiões-dentistas. Já como objetivo secundário, avaliar o impacto da pandemia do coronavírus Sars-Cov2 na saúde mental de profissionais de odontologia. A amostra foi constituída por odontólogos que estavam atuando no período pré pandemia e que concordaram em responder um questionário por meio de link em mídia social entre setembro e novembro de 2020. Adotou-se o inventário validado de Burnout de Oldenburg com perguntas relacionadas ao estresse profissional, acrescido de questões sociodemográficas. Os dados foram analisados de forma descritiva e analítica, por meio do teste do qui-quadrado $(\mathrm{p}<0,05)$. A amostra foi composta por 302 odontólogos, sendo $213(70.8 \%)$ do gênero feminino e 88 (29.2\%) do masculino, os quais participaram de uma investigação online. Dentre os profissionais avaliados, 244 (80.8\%) suspenderam as atividades por algum tempo, $226(74.8 \%)$ tinham medo de se contaminar durante o trabalho, $260(86.1 \%)$ tinham medo de transmitir o vírus a seus familiares, 91 (30.1\%) já haviam se contaminado, 163 (54\%) sentem medo quando ouvem notícias de mortes ocasionadas pelo SARS-CoV-2 e 193 (63.9\%) relataram ter os conhecimentos necessários para prevenir a contaminação. Dos odontólogos entrevistados, 46,35\% apresentaram a SB, 16,22 \% esgotamento, $15,23 \%$ o distanciamento do trabalho. A presença da SB esteve fortemente associada com a faixa etária, a atividade no setor privado, o medo de contaminar a família, o medo de se contaminar e o medo de morrer $(\mathrm{p}<0,05)$. Os achados deste estudo evidenciam que houve impacto da pandemia de COVID-19 na saúde emocional e na ocorrência da Síndrome de Burnout em cirurgiões-dentistas, especialmente devido ao medo da contaminação e da morte.

Palavras-chave: COVID-19; SARS-CoV-2; Odontologia; risco biológico; Esgotamento profissional; saúde pública. 



\begin{abstract}
Contamination caused by the SARS-CoV-2 virus puts the dentist at the top of the risk of infection. However, professionals need to continue performing dental work, being exposed to contamination risks. Thus, the present study had as its primary objective to evaluate the presence or not of BS in dentists. As a secondary objective, to evaluate the impact of the SarsCov 2 coronavirus pandemic on the mental health of dental professionals. The sample consisted of dentists who were working in the pre-pandemic period and who agreed to answer a questionnaire through a social media link, between September and November 2020. The Oldenburg Burnout validated inventory with related questions was adopted. to professional stress, added to sociodemographic issues. Data were analyzed descriptively and analytically using the chi-square test $(\mathrm{p}<0.05)$. The sample consisted of 302 dentists, $213(70.8 \%)$ female and $88(29.2 \%)$ male, who participated in an online investigation. Among the professionals evaluated, $244(80.8 \%)$ suspended their activities for some time, 226 (74.8\%) were afraid of being contaminated during work, $260(86.1 \%)$ were afraid of transmitting the virus to their families, 91 (30.1\% ) had already been contaminated, 163 (54\%) felt afraid when they heard news of death caused by SARS-CoV-2 and 193 (63.9\%) reported having the necessary knowledge to prevent the contamination. Of the dentists interviewed, $46.35 \%$ had Burnout Syndrome, $16.22 \%$ were exhausted, $15.23 \%$ had distanced themselves from work. The presence of BS was strongly associated with age group, activity in the private sector, fear of contaminating the family, fear of being contaminated and fear of dying $(\mathrm{p}<0.05)$. The findings of this study show that there was an impact of the COVID-19 pandemic on emotional health and on the occurrence of Burnout Syndrome in dentists, especially due to the fear of contamination and death.
\end{abstract}

Key-words: COVID-19; SARS-CoV-2; dentistry; biological risk; Burnout, public health. 



\section{LISTA DE ABREVIATURA E SIGLAS}

EPIs Equipamentos de proteção individuais

SB

OLBI

NHI

ADA

STROBE

GB

GC

MBI

MBI-GS

CFI

RMSEA

IDH
Síndrome de Burnout

Inventário de Burnout de Oldeburg

National Health Institute - Instituto Nacional de Saúde dos Estados Unidos

American Dental Association

Strengthening the Reporting of Observational studies in Epidemiology

Grupo com Burnout

Grupo controle (Sem Burnout)

Maslach Burnout Inventory

Maslach Burnout Inventory - General Survey

Confirmatory Fit Index

Root-Mean-Square Error of Aproximation

Índice de desenvolvimento humano 



\section{SUMÁRIO}

1 INTRODUÇÃO

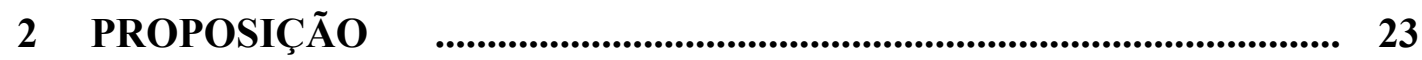

3 ARTIGO

4 DISCUSSÃO

5 CONCLUSÃO

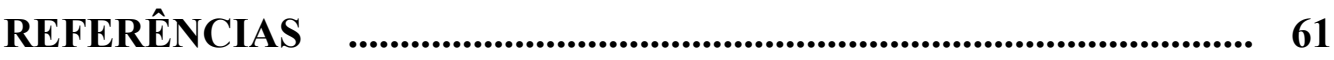

APÊNDICE

ANEXO 



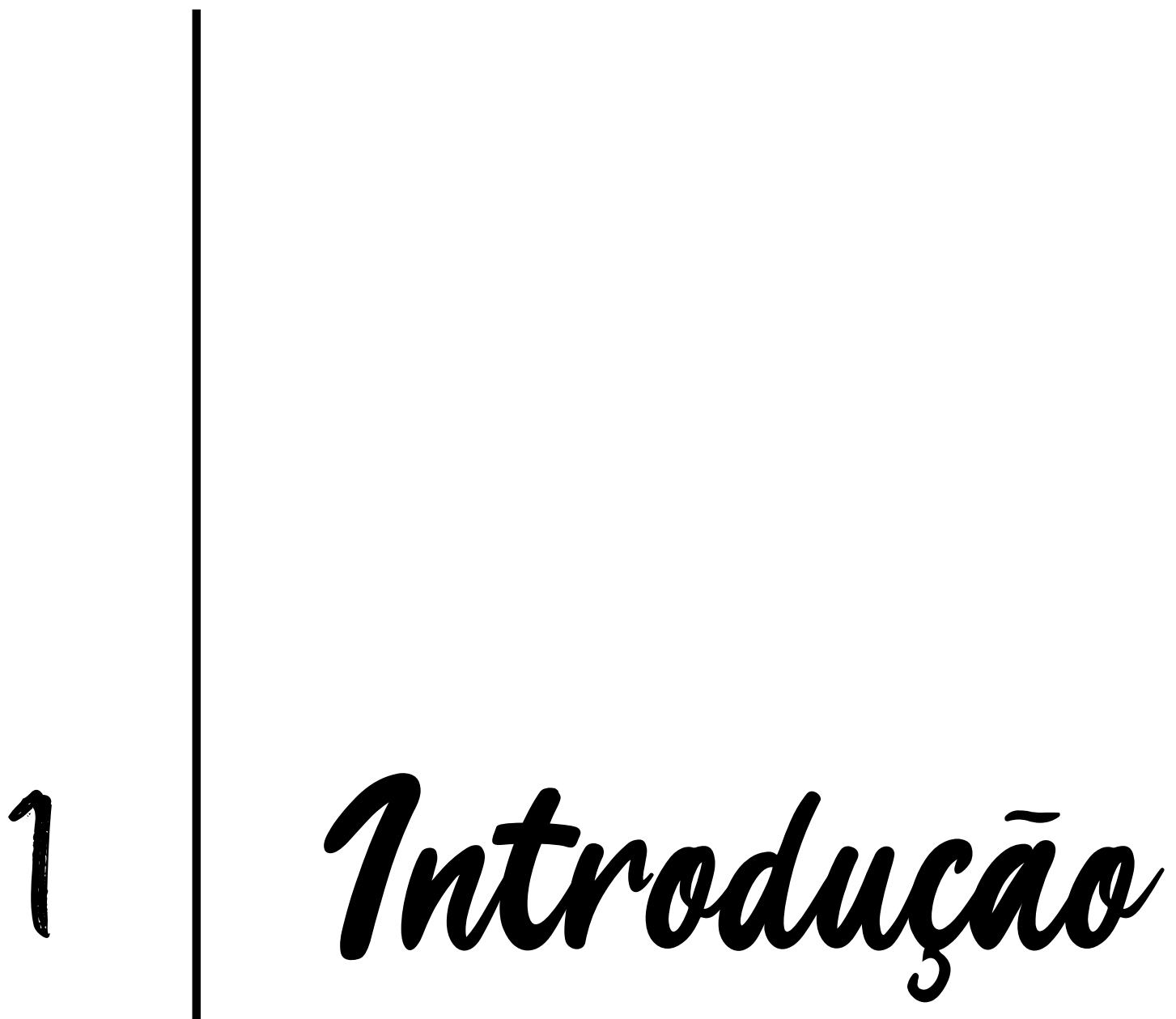





\section{1- Introdução}

A preocupação com a biossegurança sempre foi uma constante na atividade laboral da Odontologia. Os procedimentos odontológicos são realizados diretamente sob fluídos orgânicos, como sangue e saliva, os quais poderão estar contaminados por agentes biológicos patogênicos. ${ }^{1}$ Tais agentes podem causar patologias infectocontagiosas graves no profissional, bem como, de forma cruzada nos pacientes atendidos por ele se as medidas protetivas não forem realizadas adequadamente.

Entretanto, em dezembro de 2019, uma nova cepa de coronavírus ocorreu na cidade de Wuhan, na China. ${ }^{2}$ Devido a sua alta capacidade de transmissibilidade e patogenicidade, rapidamente se espalhou pelos continentes, se tornando um problema de saúde pública global. ${ }^{3}$ Tal cepa foi denominada SARS-CoV-2 e sua contaminação pode causar infecção respiratória, podendo desencadear vários distúrbios sistêmicos graves ou até mesmo levar o paciente ao óbito. $^{4}$

Estudos comprovaram que a saliva é a principal rota de transmissão do SARS-CoV-2.,5 Em virtude do surgimento da COVID-19, todos os critérios de biossegurança utilizados anteriormente precisaram ser revistos e alterados com finalidade de proteção e combate ao novo inimigo invisível. ${ }^{6} \mathrm{O}$ risco de contaminação dos odontólogos e de sua equipe de trabalho é considerado muito alto, haja vista que tais profissionais estão em um raio de contato muito próximo com os pacientes e assim sendo, ficam mais expostos aos respingos de secreções, saliva e aerossol dos equipamentos utilizados nos tratamentos odontológicos que poderão estar contaminados por vírus e bactérias patogênicas, incluindo o Sars-CoV-2. O cirurgião-dentista tem o dever e a responsabilidade de adotar medidas de prevenção e controle de infecção com a finalidade de impedir ou minimizar ao máximo o risco de transmissão de microrganismos durante qualquer procedimento odontológico realizado em seu consultório. ${ }^{7}$ As partículas virais em aerossol podem ser potencialmente mais perigosas do que as bactérias, pois podem permanecer no ar por mais tempo devido ao menor tamanho de partícula e à menor velocidade de sedimentação. ${ }^{8}$ Os aerossóis e gotículas gerados durante a intervenção odontológica podem permanecer em suspensão no ar por até 6 horas no ambiente operatório e desta forma, podem ser inalados por profissionais e pacientes, bem como podem se depositar nas superfícies circundantes e criar muitos nichos de contaminação. ${ }^{9}$

Alguns métodos foram preconizados com o intuito de promover a diminuição da dispersão dos aerossóis e consequentemente de minimizar possíveis riscos de contaminação, tais como: uso de isolamento absoluto e sucção de alta potência quando da necessidade de uso de turbina 
de alta ou baixa rotação. ${ }^{10}$ Além das medidas para diminuição da dispersão dos aerossóis, a equipe deve executar algumas condutas pré e pós atendimento, visando a diminuição da possibilidade de contaminação. No pré atendimento, o paciente deverá passar por uma triagem realizada por telefone para detectar qual é a necessidade de tratamento daquele paciente, bem como investigar possíveis sinais e sintomas de infecção, histórico de viagens e contatos com indivíduos que apresentem sintomatologia ou positivos ao COVID-19. ${ }^{10}$ As consultas deverão ser mais espaçadas com a finalidade de diminuição do contato entre os pacientes na sala de espera, como também para que toda a desinfecção da área operatória seja realizada. ${ }^{10}$

Como forma de aumentar a barreira protetora entre os profissionais e o aerossol gerado no atendimento, a equipe odontológica deverá utilizar como EPIs: máscara cirúrgica sobreposta a máscara N-95, gorro e pijama cirúrgico, óculos de proteção, face shield, sapatos de borracha impermeáveis ou propé, luvas e avental cirúrgico descartável. ${ }^{10}$ Vale ressaltar a necessidade que além da utilização de todos os EPIs de forma correta, é importante que haja uma sequência correta na paramentação (Figura 1) e desparamentação (Figura 2) de todos os equipamentos com a finalidade de evitar o contato e contaminação com fluídos e agentes patogênicos. ${ }^{10}$

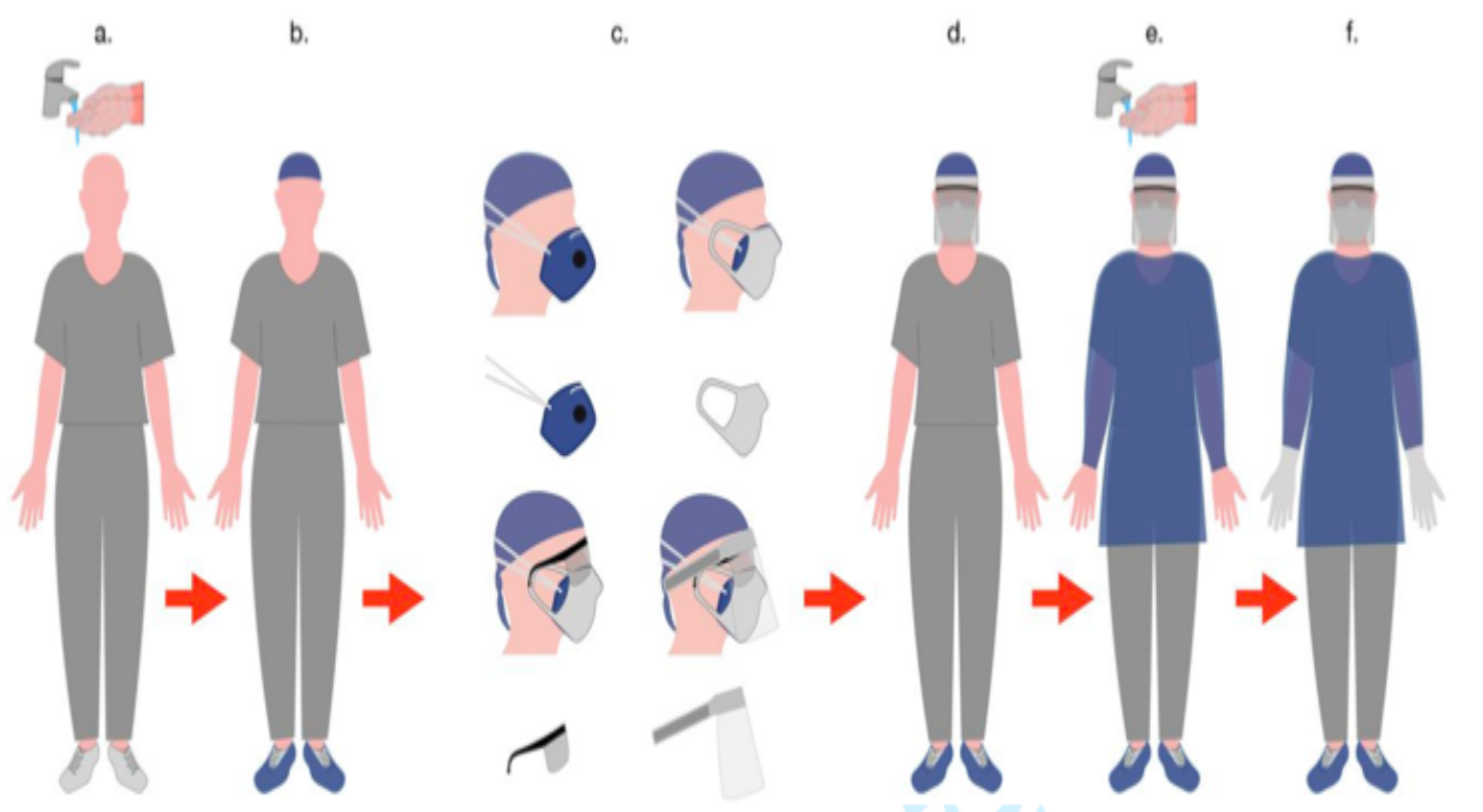

Figura 1 - Passo a passo de paramentação das EPIs. Fonte: Marcelo Salmazo Castro., et al. "Coronavirus Disease 2019 Biological Risk and Clinical Care Protocol in Dentistry: A Systematic Review". Acta Scientific Dental Sciences 5.5 (2021): 28-43. 


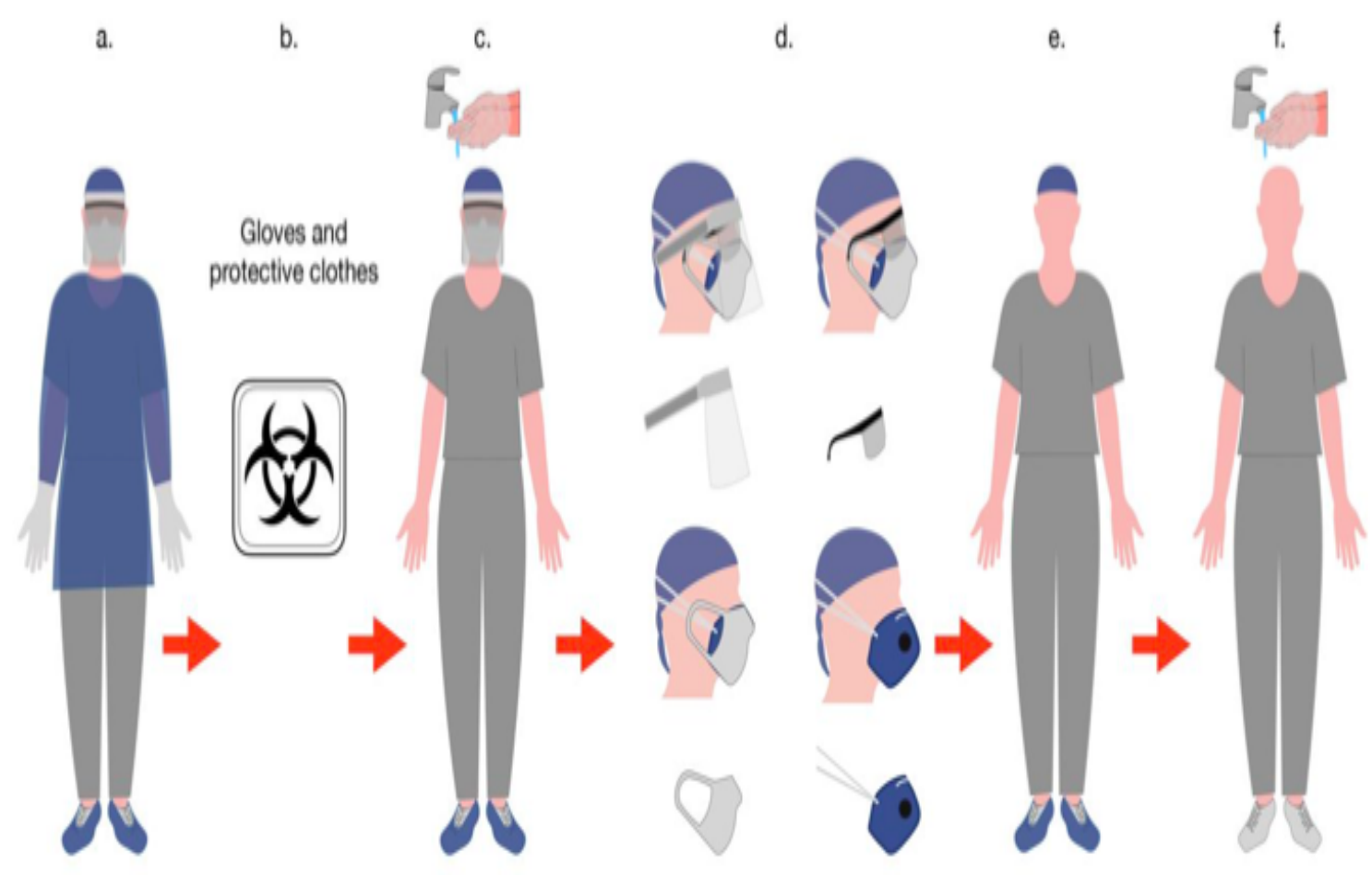

Figura 2 - Passo a passo de desparamentação das EPIs . Fonte: Marcelo Salmazo Castro., et al. "Coronavirus Disease 2019 Biological Risk and Clinical Care Protocol in Dentistry: A Systematic Review". Acta Scientific Dental Sciences 5.5 (2021): 28-43. ${ }^{10}$

A área de recepção deve ser adequadamente arejada, ventilada e filtros de ar são recomendados. A sala deve passar por processo de higienização por pelo menos duas vezes ao dia e os itens não essenciais tais como revistas, jornais, objetos de decoração devem ser removidos, além da execução de um rigoroso protocolo de desinfeção de superfícies nas bancada de atendimento, cadeira e equipo odontológico. ${ }^{10}$ Todo esse protocolo de atendimento deve fazer parte da rotina de qualquer consultório, afim de que o profissional possa manter a sua importante missão na manutenção e promoção de saúde sem ser um vetor de disseminação e transmissão de patógenos.

$\mathrm{Na}$ ocorrência de epidemias, o número de pessoas infectadas pela infecção tende ser menor do que aquelas que tiveram um comprometimento psicológico originado pelas mesmas. ${ }^{11}$ Contudo, em virtude do ineditismo vivido pela nossa geração em relação a necessidade do distanciamento e isolamento social como forma de prevenção ao SARS-CoV-2, o impacto dessa pandemia pode ser ainda maior, levando à hipótese de "pandemia de medo e estresse". ${ }^{11} \mathrm{O}$ medo do contágio durante o exercício profissional, bem como o de ser o agente transmissor a seus familiares, aliados a responsabilidade e a sua necessidade econômica podem ser um agravante psicológico neste profissional. ${ }^{12}$ 
Uma nova mutação do SARS-CoV-2 designada variante de preocupação B.1.1.7 foi identificada no Reino Unido no final de 2020, e foi responsável por uma proporção crescente de casos. Enquanto a maioria das linhagens de SARS-CoV-2 mostraram poucas mutações, o B.1.1.7 acumulou 23 alterações em todo o genoma, incluindo uma mutação que afeta a proteína Spike que aumenta a afinidade de ligação ao receptor ACE2 e consequentemente o seu poder de transmissibilidade. ${ }^{13}$ Outras variantes foram encontradas na África do Sul e no Brasil fazendo com que a vigilância contínua do vírus e o redesenho rápido de novas vacinas para combater novas variantes sejam cruciais para o combate do COVID-19. ${ }^{14}$ Todas essas incertezas relacionadas ao controle e formas de proteção à pandemia podem aumentar ainda mais o medo e o stress das pessoas e de uma forma mais preocupante nos profissionais de saúde que trabalham diretamente expostos à contaminação.

A SB é um estado de colapso físico ou mental causado pelo excesso de trabalho ou estresse contínuo e prolongado. O termo Burnout é originário da língua Inglesa e é a fusão de duas palavras, "Burn" (queimar) e "out" ( externo), ou seja, o termo se refere à queima das energias físicas e emocionais do profissional, o qual se sente sugado e sem estímulo na sua rotina de trabalho, perdendo o entusiasmo e o interesse pelo mesmo, prejudicando o seu desempenho e a qualidade das atividades que exerce. ${ }^{15}$ A Síndrome de Burnout é responsável por uma variedade de consequências negativas, incluindo depressão e risco de erros profissionais. A SB está associada a um estado de frustração com o ambiente de trabalho, ou quando o profissional se sente inábil para exercer a sua profissão, sem o conhecimento científico ou técnico para executar as suas atividades, bem como quando as situações de conflito entre os membros da equipe não possuem mais estratégias para serem enfrentadas e solucionadas. ${ }^{16}$

Embora a SB tenha sido descoberta e estudada muito antes da pandemia, com o surgimento do COVID-19, novos fatores de stress, medo e insegurança foram adicionados aos já existentes na rotina dos profissionais de saúde, aumentando os fatores de risco ao desenvolvimento e instalação da SB. ${ }^{17}$

Maslach et al caracterizou a Síndrome de Burnout através de três elementos constituintes. O primeiro é representado pela exaustão emocional (stress e exaustão física). Os outros dois são: despersonalização (caracterizada por uma atitude distanciada, negativa, interações distantes com os outros) e o sentimento de diminuição da realização pessoal (sentimentos de incompetência e inabilidade profissional). ${ }^{18}$

Até 1999, o MBI-GS era o um dos inventários mais usados para aferir a presença da Síndrome de Burnout. Entretanto, pesquisadores argumentavam que o MBI-GS poderia trazer o possível enviesamento das respostas, já que as questões são apresentadas apenas no sentido 
negativo para as dimensões exaustão e despersonalização e, no sentido positivo, para a dimensão eficácia no trabalho. Outra falha apontada pelos autores refere-se a dimensão exaustão, que mensura somente aspectos afetivos, ignorando aspectos físicos e cognitivos do trabalho. ${ }^{19}$ Com a finalidade de impedir respostas com viés que descaracterizassem a pesquisa e os resultados da SB, em 1999 Evangelia Demerouti desenvolveu o Inventário de Burnout de Oldeburg (Inventário de OLBI). O OLBI foi desenvolvido com 16 perguntas, 8 delas medindo a exaustão e as outras 8 o distanciamento profissional. Em cada uma das dimensões, metade das perguntas tem caráter afirmativo e a outra metade negativo, impedindo assim o viés de mensuração. ${ }^{19}$

Por se tratar de um evento recente, não há na literatura evidências científicas que avaliem o impacto da pandemia de SARS-CoV-2 e a síndrome de Burnout em cirurgiões-dentistas. Por isso, é muito importante que estudos com essa temática sejam realizados com o intuito de aferir as condições emocionais e a Síndrome de Burnout nos odontólogos durante o enfrentamento da pandemia. Essas informações são relevantes tanto para o conhecimento da situação, como para o direcionamento de outros estudos, proporcionando evidências que sinalizem as formas de tratamento e prevenção da Síndrome de Burnout. 



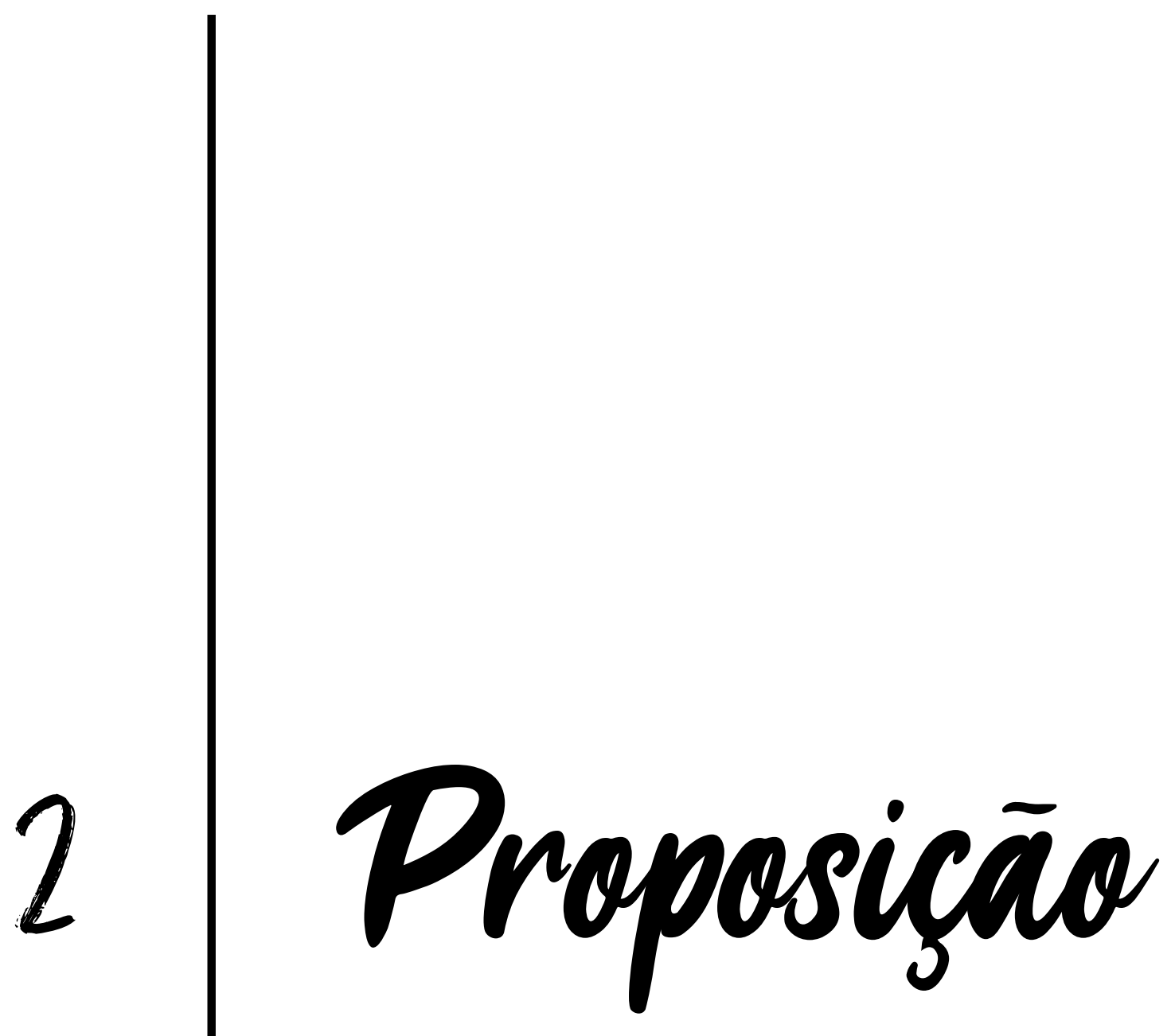





\section{2- Proposição}

\subsection{Objetivo Primário:}

O objetivo primário foi avaliar a presença ou não da Síndrome de Burnot (SB) nos cirurgiões-dentistas e se havia associações da SB com as variáveis relacionadas à pandemia

\subsection{Objetivo Secundário:}

O objetivo secundário desta pesquisa foi avaliar o impacto da pandemia de coronavírus SARS-CoV-2 na saúde mental dos profissionais de odontologia. 



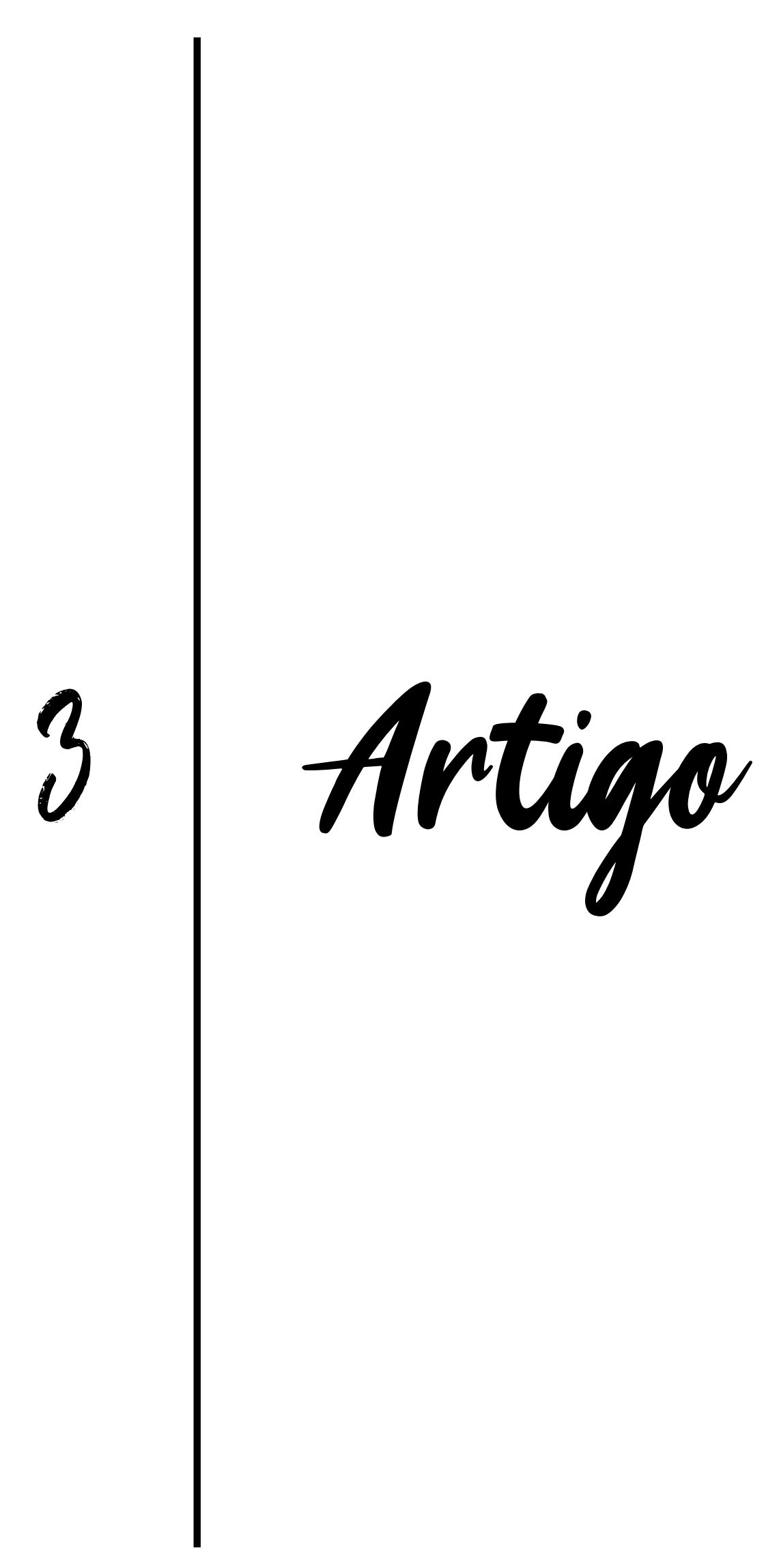

Artigo 





\title{
Impacto da pandemia de SARS-CoV-2 (COVID-19) na saúde emocional e na Síndrome de Burnout em cirurgiões-dentistas no Brasil
}

\author{
Marcelo Salmazo Castro ${ }^{1}$ (https://orcid.org/0000-0002-9601-9069) \\ Silvia Helena de Carvalho Sales-Peres ${ }^{1}$ (https://orcid.org/0000-0003-3811-7899) \\ ${ }^{1}$ Departamento de Odontopediatria, Ortodontia e Saúde Coletiva, Faculdade de Odontologia \\ de Bauru, Universidade de São Paulo, Bauru, São Paulo, Brasil.
}

\section{RESUMO}

A contaminação causada pelo vírus SARS-CoV-2 coloca o cirurgião-dentista no topo do risco de infecção. Entretanto, os profissionais necessitam continuar realizando o trabalho odontológico, sendo expostos aos riscos de contaminação. Dessa forma, o presente estudo teve por objetivo primário avaliar a presença ou não da SB nos cirurgiões-dentistas. Já como objetivo secundário, avaliar o impacto da pandemia do coronavírus Sars-Cov2 na saúde mental de profissionais de odontologia. A amostra foi constituída por odontólogos que estavam atuando no período pré pandemia e que concordaram em responder um questionário por meio de link em mídia social entre setembro e novembro de 2020. Adotou-se o inventário validado de Burnout de Oldenburg com perguntas relacionadas ao estresse profissional, acrescido de questões sociodemográficas. Os dados foram analisados de forma descritiva e analítica, por meio do teste do qui-quadrado $(\mathrm{p}<0,05)$. A amostra foi composta por 302 odontólogos, sendo $213(70.8 \%)$ do gênero feminino e $88(29.2 \%)$ do masculino, os quais participaram de uma investigação online. Dentre os profissionais avaliados, 244 (80.8\%) suspenderam as atividades por algum tempo, $226(74.8 \%)$ tinham medo de se contaminar durante o trabalho, $260(86.1 \%)$ tinham medo de transmitir o vírus a seus familiares, 91 (30.1\%) já haviam se contaminado, 163 (54\%) sentem medo quando ouvem notícias de mortes ocasionadas pelo SARS-CoV-2 e 193 (63.9\%) relataram ter os conhecimentos necessários para prevenir a contaminação. Dos odontólogos entrevistados, 46,35\% apresentaram a SB, 16,22 \% esgotamento, 15,23\% o distanciamento do trabalho. A presença da SB esteve fortemente associada com a faixa etária, a atividade no setor privado, o medo de contaminar a família, o medo de se contaminar e o medo de morrer $(\mathrm{p}<0,05)$. Os achados deste estudo evidenciam que houve impacto da pandemia de COVID-19 na saúde emocional e na ocorrência da Síndrome de Burnout em cirurgiões-dentistas, especialmente devido ao medo da contaminação e da morte.

Palavras-chave: COVID-19; SARS-CoV-2; Odontologia; esgotamento profissional, saúde púbica. 


\begin{abstract}
Contamination caused by the SARS-CoV-2 virus puts the dentist at the top of the risk of infection. However, professionals need to continue performing dental work, being exposed to contamination risks. Thus, the present study had as its primary objective to evaluate the presence or not of BS in dentists. As a secondary objective, to evaluate the impact of the SarsCov 2 coronavirus pandemic on the mental health of dental professionals. The sample consisted of dentists who were working in the pre-pandemic period and who agreed to answer a questionnaire through a social media link, between September and November 2020. The Oldenburg Burnout validated inventory with related questions was adopted. to professional stress, added to sociodemographic issues. Data were analyzed descriptively and analytically using the chi-square test $(\mathrm{p}<0.05)$. The sample consisted of 302 dentists, $213(70.8 \%)$ female and $88(29.2 \%)$ male, who participated in an online investigation. Among the professionals evaluated, $244(80.8 \%)$ suspended their activities for some time, $226(74.8 \%)$ were afraid of being contaminated during work, $260(86.1 \%)$ were afraid of transmitting the virus to their families, 91 (30.1\% ) had already been contaminated, 163 (54\%) felt afraid when they heard news of death caused by SARS-CoV-2 and 193 (63.9\%) reported having the necessary knowledge to prevent the contamination. Of the dentists interviewed, 46.35\% had Burnout Syndrome, $16.22 \%$ were exhausted, $15.23 \%$ had distanced themselves from work. The presence of BS was strongly associated with age group, activity in the private sector, fear of contaminating the family, fear of being contaminated and fear of dying $(p<0.05)$. The findings of this study show that there was an impact of the COVID-19 pandemic on emotional health and on the occurrence of Burnout Syndrome in dentists, especially due to the fear of contamination and death.
\end{abstract}

Keywords: COVID-19; SARS-CoV-2; dentistry; Burnout professional, public health. 


\section{1- Introdução}

A COVID-19 é uma doença viral com sintomas semelhantes aos da gripe e foi inicialmente observada entre as pessoas residentes em Wuhan, província de Hubei na China. ${ }^{1}$ Em 11 de fevereiro de 2020 a OMS usou o termo COVID-19 para descrever a última cepa de coronavírus. ${ }^{2}$ Em 11 de março de 2020 a Organização Mundial da Saúde declarou estado de Pandemia pela elevação da contaminação da infecção causado pelo SARS-CoV-2. ${ }^{3}$ Esse vírus é composto estruturalmente de um grande RNA único e de cadeia positiva como seu genoma. ${ }^{4}$ Os sinais clínicos em seres humanos infectados por COVID19 são sintomas de febre, tosse, mialgia ou fadiga, imagem anormal da tomografia computadorizada (imagem vítrea) e dificuldade respiratória grave, enquanto sintomas menos comuns incluem produção de escarro, dor de cabeça, hemoptise e diarreia. ${ }^{5} \mathrm{O}$ primeiro ensaio clínico com intuito de desenvolver uma vacina capaz de imunizar a população foi desenvolvido pelo Instituto Nacional de Saúde (NHI) dos EUA. ${ }^{6}$ Haja vista que o sistema imunológico tem a função de defesa do corpo, pacientes idosos com doenças debilitantes crônicas têm um risco maior de serem infectados em comparação com indivíduos jovens e saudáveis com um sistema imunológico forte. ${ }^{7}$ Inicialmente, acreditava-se haver uma rota zoonótica de transmissão; no entanto, uma nova via de transmissão pessoa a pessoa está causando a propagação rápida da doença pelos diferentes continentes. ${ }^{8}$ Em 14 de dezembro de 2020, o Reino Unido reportou o surgimento de uma nova variante do SARS-CoV-2 denominada de B.1.1.7. Em 2021, a B.1.1.7 foi detectada em mais de 30 países, incluindo o Brasil. Esta variante tem como característica uma mutação da proteína Spike, responsável pela melhora na capacidade de ligação viral as células humanas, a qual foi responsável pelo aumento do potencial de transmissibilidade do vírus. ${ }^{9}$ Fato este, que deve gerar a necessidade do aumento nas medidas protetivas e do aceleramento das vacinações para impedir piora da contaminação pela COVID-19.

\section{Covid19 na Odontologia}

O ambiente de trabalho contaminado é o principal fator para a transmissão das novas cepas de vírus. ${ }^{10}$ Em um ambiente odontológico onde o cirurgião-dentista e seus equipamentos estão muito próximos do paciente e na maioria dos procedimentos há produção de aerossol pelo uso do alta-rotação, a probabilidade de contaminação por microgotas de um paciente infectado é alta, além do risco de transmissão cruzada. Na rotina comum de qualquer consultório odontológico já são utilizadas normas rígidas de biossegurança pelo fato de vários outros vírus e bactérias estarem presentes nos fluídos salivares e corpóreos dos pacientes. Entretanto, devido ao alto poder de disseminação característico do SARS-CoV-2, algumas 
medidas adicionais se fazem necessárias. Segundo a America Dental Association (ADA), é necessário incluir nos protocolos de pré-atendimento odontológicos o histórico de contatos recentes, realizar o registro da temperatura corpórea e avaliar os sinais e sintomas de possíveis estados gripais dos pacientes e em caso de suspeita positiva, não realizar o atendimento. Após passar pela entrevista de triagem e análise física, antes de qualquer procedimento, deve-se adotar um protocolo rigoroso de desinfecção do ambiente clínico. Os procedimentos clínicos, quando possível, devem ser realizados com instrumentais manuais, com isolamento absoluto e com o auxílio de sucção com bomba de alta potência com o intuito de minimizar a disseminação produzida pelo aerossol das turbinas de alta-rotação e/ou baixa-rotação. Assim como realizar a frequente desinfecção do campo de trabalho e maçanetas. ${ }^{11}$

\section{Aspectos psicológicos da pandemia nos odontólogos}

O volume massivo de informações negativas e preocupantes dos efeitos causados pela pandemia difundidas nos meios de comunicação geram receio e medo em toda a população. Porém, os profissionais de saúde por estarem em contato mais direto com possíveis infectados, o medo e a ansiedade são as emoções que mais os afligem na rotina cotidiana.

Ansiedade leve é natural e promove comportamentos preventivos e de resguardo. ${ }^{12}$ Por isso, é natural que os cirurgiões-dentistas adquiram um forte receio de serem contaminados por seus pacientes. A dedicação ou a preocupação em tempo integral, aliados a extrema responsabilidade e ao stress profissional evidenciam a necessidade da compreensão das condições mentais relacionadas ao comportamento humano no contexto da saúde do trabalhador. Além do adequado diagnóstico de elementos estressores que possam comprometer resultados profissionais, bem como a saúde do odontólogo.

A percepção do profissional sobre a discrepância entre os seus esforços realizados e os objetivos alcançados no trabalho, podem gerar uma série de sentimentos de frustração e estresse interpessoal. Quando a exposição aos elementos estressores e a frustração ocorrem por prolongado período de tempo, pode desencadear o desenvolvimento da síndrome de Burnout. ${ }^{13}$ A Síndrome de Burnout é uma síndrome multifatorial constituída por exaustão emocional, desumanização e reduzida realização pessoal no trabalho que ocorre como resultado do estresse ocupacional crônico. ${ }^{14}$

O odontólogo devido aos riscos ocupacionais, o estado de stress e alerta constante, tem sido apontado na literatura como um profissional com alto risco de desenvolvimento da Síndrome de Burnout. ${ }^{15,16,17}$ Esses fatores contribuem para o aumento do sentimento de baixa satisfação profissional, queda da produtividade e diminuição da qualidade dos serviços elaborados pelos profissionais acometidos por esta Síndrome. ${ }^{15,16,17}$ 
O profissional já enfrenta pressão e estresse na atividade laboral que podem ser ampliados pelos riscos da contaminação do SARS-CoV-2. Os cirurgiões-dentistas vem travando uma luta diária para manter o equilíbrio emocional. No sentido de auxiliar, eles devem estar informados sobre as evidencias científicas recentes referentes as formas de contaminação e propagação do vírus, do uso de EPIs recomendados, além de seguir as diretrizes recomendadas pelos órgãos sanitários competentes, contribuindo assim, para a diminuição da transmissão e propagação do vírus. Entretanto, até o presente momento não há muitos estudos envolvendo a saúde mental do cirurgião-dentista após a instalação da pandemia da COVID-19. Ademais, os profissionais necessitam continuar realizando o trabalho odontológico, sendo expostos aos riscos diretos de contaminação. O conhecimento das condições de saúde mental do cirugião-dentista frente ao desafio da pandemia, pode nortear os cuidados a serem adotados na rotina diária. Dessa forma, o presente estudo teve por objetivo primário avaliar o impacto da pandemia do coronavírus Sars-Cov2 na saúde mental de profissionais de odontologia. Já como objetivo secundário, avaliar a presença ou não da síndrome de Burnout nesses profissionais.

\section{2-Materiais e Métodos}

Esta pesquisa seguiu as diretrizes STROBE para estudos transversais. ${ }^{18}$

\section{1-Aspectos Éticos}

Foram adotadas às diretrizes da Declaração de Helsinque para a realização deste estudo, que foi submetido e aprovado previamente pelo Comitê de Ética em Pesquisa em Seres Humanos da Faculdade de Odontologia de Bauru da Universidade de São Paulo (CAAE 35177120.9.0000.5417). Todos os participantes preencheram um formulário do Google Forms, ao qual continha o Termo de Consentimento Livre e Esclarecido assinado pelos voluntários de forma virtual, concordando em participar desta pesquisa.

\section{2 - Amostra}

A amostra foi constituída por cirurgiões-dentistas inscritos no Conselho Federal de Odontologia que aceitaram responder ao questionário da pesquisa. Os convites para participação foram disponibilizados nas redes sociais dos pesquisadores, através de um link para preenchimento de um formulário contendo o questionário proposto $(n=302)$. Os indivíduos após a avaliação da presença ou ausência da Síndrome de Burnout foram divididos em dois grupos: GB- grupo com Burnout e GC-grupo controle (sem Burnout). A coleta de dados ocorreu nos meses de setembro e novembro de 2020. 


\section{3- Critérios de elegibilidade:}

\section{Inclusão}

O critério de inclusão foi ser cirurgião-dentista regularmente inscrito nos Conselhos de Odontologia e que atue em clínica ou consultório odontológico público ou privado.

\section{Exclusão}

Como critério de exclusão foi estabelecido que o questionário que tivesse alguma pergunta sem resposta seria excluído.

\section{4- Variáveis do Estudo}

$\mathrm{Na}$ amostra, foram obtidas informações iniciais a respeito das condições sócio demográficas, tais como: gênero, faixa etária, local de trabalho, formação acadêmica, tempo de graduação e de carga horária de trabalho. Na segunda parte do questionário, os participantes responderam à respeito das percepções, medos e atitudes dos odontólogos relacionados à pandemia do Sars-Cov2. Na última parte do formulário, foi avaliado a SB através do Inventário de Burnout de Oldenburg (OLBI). ${ }^{17}$

O questionário de OLBI é um instrumento validado por pesquisadores de todo o mundo e é utilizado em duas dimensões, avaliando a exaustão e o distanciamento do profissional através de oito perguntas em cada dimensão, sendo quatro afirmações positivas e quatro negativas nos dois blocos. ${ }^{17}$ Para cada ítem, existem quatro possibilidades de resposta que serão avaliadas através da escala de Likert variando de "discordo completamente" à "concordo completamente". 19

O inventário de OLBI, diferentemente do questionário MBI ou MBI-GS, não se restringe exclusivamente aos aspectos afetivos da exaustão, mas sim, incorpora questões relacionadas também ao prisma físico e cognitivo, facilitando a aplicação do instrumento para os trabalhadores que realizam trabalho físico e aqueles cujo trabalho é principalmente sobre processamento de informações. ${ }^{20}$

Para a caracterização da presença ou não da SB foi utilizada a proposta de Peterson et al ${ }^{21}$, onde escores médios $\geq 2,25$ na dimensão Exaustão (referente as questões de 1 à 8) e $\geq 2,1$ na dimensão Distanciamento (referente às questões de 9 à 16) serão considerados altos e os participantes serão classificados conforme apresentado na tabela 1. 


\begin{tabular}{ccc}
\hline & Dimensão & \\
Exaustão & Distanciamento & Classificação \\
\hline Baixo & Baixo & Sem Burnout \\
Baixo & Alto & Com distanciamento \\
Alto & Baixo & Com esgotamento \\
Alto & Alto & Com Burnout \\
\hline
\end{tabular}

Para a realização desta pesquisa, os participantes foram divididos em dois grupos: GB (Grupo Burnout) e GC (Grupo sem Burnout). O questionário de OLBI é divido em duas dimensões, exaustão e distanciamento. De acordo com os escores delineados na escala de Likert em cada dimensão, foi utilizada a escala de Peterson onde os participantes que obtivessem escores médios $\geq 2,25$ na dimensão Exaustão (referente as questões de 1 à 8 ) e $\geq 2,1$ na dimensão Distanciamento (referente às questões de 9 à 16) foram considerados altos. ${ }^{21}$ No grupo GB, foram inseridos somente os participantes que foram classificados com escores altos nas duas dimensões (exaustão e distanciamento). Já o grupo sem Burnout (GC), foram inseridos os participantes que apresentaram escores altos somente na dimensão exaustão, somente na dimensão distanciamento ou os participantes com escores baixo de exaustão e distanciamento. (Figura 1)

\section{5- Análises Psicométricas}

Para a comprovação da eficácia e confiabilidade do modelo de questionário e da amostra, foi realizado uma análise fatorial confirmatória através da verificação da qualidade pelo teste qui-quadrado de ajustamento $\left(\chi^{2}\right)$ e das medidas de CFI e RMSEA levando-se em conta os critérios adotados por Kline. ${ }^{22}$

\section{6- Análise Estatística}

Os resultados encontrados referente às características sociodemográficas e os relativos à pandemia de Sars-Cov2 foram analisados através de análise descritiva e apresentados em tabelas. A prevalência da SB foi estimada por ponto e para a avaliação da associação entre a prevalência da SB e as variáveis de interesse, foi realizado o teste de qui-quadrado $\left(\chi^{2}\right)$, sendo adotado o nível de significância de 5\%. 


\section{3- Resultados}

\section{1- Análise Sociodemográfica}

A amostra foi composta por 302 odontólogos, sendo 214 do gênero feminino (70,8\%) e 88 do masculino (29,2\%). A faixa etária foi dividida em: 20-30 anos ( $\mathrm{n}=54 ; 17,9 \%), 31-40$ anos $(n=65 ; 21,5 \%), 41-50$ anos $(n=112 ; 37,1 \%), 51-60$ anos $(n=61 ; 20,2 \%)$ e 60 ou mais $(n=10$; $3,3 \%$ ). Com relação à instituição de formação de graduação, instituições públicas foram 185 (61,3\%) e privadas 117 (38,7\%). Já em relação ao setor de trabalho, 199 (66,1\%) trabalham exclusivamente em instituições públicas, 46 (15,3\%) somente no setor privado e $56(18,6 \%)$ trabalham nos dois setores. Quanto ao tempo de graduação, foram $50(16,6 \%)$ entrevistados com até 5 anos de formados, $41(13,6 \%)$ entre 6 e 10 anos, $29(9,6 \%)$ entre 11 e 15 anos, 34 $(11,3 \%)$ entre 16 e 20 anos, $42(13,9 \%)$ entre 21 e 25 anos, 59 (19,5\%) entre 26 e 30 anos e, 47 $(15,6 \%)$ com mais de 30 anos de graduado. Em relação à atuação clínica, 172 (57\%) eram especialistas e $130(43 \%)$ eram clínicos-geral. Quando perguntados sobre a carga horária de trabalho semanal encontramos, $36(11,9 \%)$ participantes que declararam trabalhar de 1 à 10 horas, $30(9,9 \%)$ de 11 à 20 horas, $45(14,9 \%)$ de 21 à 30 horas, $98(32,5 \%)$ de 31 à 40 horas, $71(23,5 \%)$ de 41 à 50 horas e $22(7,3 \%)$ com mais de 50 horas.

\section{2- Percepção dos odontólogos frente à Pandemia de Sars-Cov-2}

Com a instalação da Pandemia de Sars-Cov-2, muitos profissionais da odontologia se sentiram expostos a uma possível contaminação durante a execução de procedimentos odontológicos. Através deste questionário, pudemos avaliar que 244 (80,8\%) odontólogos suspenderam as atividades por algum tempo, sendo que 205 (67,9\%) já retornaram as atividades normais e $39(12,9 \%)$ encontravam-se ainda com as atividades suspensas até o período de captação dos dados do questionário. Em relação ao medo de ser infectado durante o trabalho, $226(74,8 \%)$ relataram ter medo da contaminação e 281 (93\%) dos profissionais estavam adiando as consultas de pacientes com sintomas suspeitos. Também relataram que $260(86,1 \%)$ dos entrevistados tinham receio de se contaminar e transmitir o vírus a seus familiares; 163 (54\%) sentem medo quando ouvem relatos de mortes ocasionadas pelo COVID-19. 213 (70,5\%) conheciam algum odontólogo que foi contaminado pelo vírus e $91(30,1)$ dos indivíduos entrevistados já testaram positivo ao Sars-Cov-2. Em relação aos conhecimentos necessários de prevenção, $193(63,9 \%)$ relataram ter os conhecimentos protetivos à contaminação do vírus. Devido ao surgimento da pandemia, 234 (77,5\%) desejam seguir na profissão, trabalhando da mesma maneira apenas redobrando os cuidados de biossegurança. Em contrapartida, $42(13,9 \%)$ desejam diminuir a jornada de trabalho, 10 (3,3\%) irão trabalhar 
somente com atividades não invasivas, $12(4 \%)$ desejam buscar outras alternativas de trabalho dentro da carreira odontológica e 4 (1,3\%) querem deixar a profissão. (Tabela 2)

Tabela 2 - Percepções dos odontólogos à pandemia de Sars-Cov-2

\begin{tabular}{|c|c|c|c|}
\hline Percepções dos Cirurgiões-Dentistas & Sim & Não & $\begin{array}{l}\text { Às vezes } \\
\text { / Talvez }\end{array}$ \\
\hline $\begin{array}{l}\text { Você tem medo de ser infectado com o COVID-19 } \\
\text { durante a realização de um procedimento } \\
\text { odontológico? }\end{array}$ & $226(75 \%)$ & $76(25 \%)$ & - \\
\hline $\begin{array}{l}\text { Você tem medo de se contaminar durante o seu } \\
\text { trabalho e transmitir o vírus a seus familiares? }\end{array}$ & $260(86 \%)$ & $42(14 \%)$ & - \\
\hline Você já testou positivo ao COVID-19? & $91(30 \%)$ & $211(70 \%)$ & - \\
\hline $\begin{array}{l}\text { Você NÃO está realizando algum procedimento } \\
\text { mais invasivo por medo de se contaminar? }\end{array}$ & $111(36 \%)$ & $191(64 \%)$ & - \\
\hline $\begin{array}{l}\text { Você sente medo quando ouve que pessoas estão } \\
\text { morrendo por ação do SARS-CoV-2? }\end{array}$ & $163(54 \%)$ & $44(16 \%)$ & $95(30 \%)$ \\
\hline $\begin{array}{l}\text { Você suspendeu todos os atendimentos em algum } \\
\text { momento da pandemia? }\end{array}$ & $244(81 \%)$ & $58(19 \%)$ & - \\
\hline $\begin{array}{l}\text { Você acha que possui os conhecimentos protetivos } \\
\text { necessários em relação ao COVID-19? }\end{array}$ & $193(64 \%)$ & $35(12 \%)$ & $74(24 \%)$ \\
\hline
\end{tabular}

\section{3 - Análise do questionário para Síndrome de Burnout}

A distribuição das respostas dadas a cada questão do OLBI pelos participantes está exposta na Tabela 3. Cabe esclarecer que todos os participantes responderam a todas as perguntas. A confiabilidade do Inventário de OLBI pode ser verificada pela Alfa de Cronbach $(\alpha=0,916)$, CFA $(0,905)$, onde números $>0,90$ são desejáveis e RMSEA $(0,0874)$ com índices próximos a $0,09 .^{22,23}$

Dentre os principais achados, podemos notar que a maioria dos participantes se sentem cansados antes de chegar ao trabalho (61\%); precisam de mais tempo para relaxar do que antes (68\%); que as vezes se sentem fartos de suas tarefas e que depois do trabalho sentem-se sem energia (64\%). Por outro lado, a maioria também consegue suportar muito bem as pressões do trabalho (64\%); conseguem administrar bem a quantidade de trabalho $(75 \%)$ e encontram com frequência casos novos e interessantes (77\%). Dos odontólogos entrevistados, 140 (46\%) 
apresentaram a Síndrome de Burnout, 49 (16\%) esgotamento, 46 (15\%) o distanciamento. (Tabela 3)

Tabela 3 - Distribuição das respostas ao questionário de OLBI

\begin{tabular}{|c|c|c|c|c|}
\hline Avaliação Burnout & $\begin{array}{l}\text { Discordo } \\
\text { completamente }\end{array}$ & Discordo & Concordo & $\begin{array}{c}\text { Concordo } \\
\text { completamente }\end{array}$ \\
\hline $\begin{array}{l}\text { Há dias que me sinto } \\
\text { cansado antes de chegar ao } \\
\text { trabalho }\end{array}$ & $33(11 \%)$ & $83(27,6 \%)$ & $127(42,2 \%)$ & $58(19,3 \%)$ \\
\hline $\begin{array}{l}\text { Depois do trabalho preciso } \\
\text { de mais tempo para relaxar }\end{array}$ & $25(8,3 \%)$ & $71(23,6 \%)$ & $134(44,5 \%)$ & $71(23,6 \%)$ \\
\hline $\begin{array}{l}\text { Consigo suportar muito bem } \\
\text { as pressões do meu trabalho }\end{array}$ & $14(4,7 \%)$ & $95(31,6 \%)$ & $156(51,8 \%)$ & $36(12 \%)$ \\
\hline $\begin{array}{l}\text { Durante o meu trabalho, } \\
\text { sinto-me emocionalmente } \\
\text { esgotado }\end{array}$ & $40(13,3 \%)$ & $128(42,5 \%)$ & $93(30,9 \%)$ & $40(13,3 \%)$ \\
\hline $\begin{array}{l}\text { Depois do trabalho, tenho } \\
\text { energia para o lazer }\end{array}$ & $39(13 \%)$ & $114(37,9 \%)$ & $120(39,9 \%)$ & $28(9,3 \%)$ \\
\hline $\begin{array}{l}\text { Quando trabalho, sinto-me } \\
\text { geralmente com energia }\end{array}$ & $17(5,6 \%)$ & $79(26,2 \%)$ & $179(59,5 \%)$ & $26(8,6 \%)$ \\
\hline $\begin{array}{l}\text { Depois do trabalho, sinto-me } \\
\text { cansado e sem energia }\end{array}$ & $20(6,7 \%)$ & $52(17,5 \%)$ & $141(47,5 \%)$ & $48(16,2 \%)$ \\
\hline $\begin{array}{l}\text { Consigo administrar bem a } \\
\text { quantidade de trabalho }\end{array}$ & $11(3,7 \%)$ & $64(21,3 \%)$ & $200(66,4 \%)$ & $26(8,6 \%)$ \\
\hline $\begin{array}{l}\text { Encontro com frequência } \\
\text { casos novos e interessantes }\end{array}$ & $7(2.3 \%)$ & $61(20,3 \%)$ & $200(66,4 \%)$ & $32(10,7 \%)$ \\
\hline $\begin{array}{l}\text { Cada vez falo com mais } \\
\text { frequência de forma negativa } \\
\text { do meu trabalho }\end{array}$ & $79(26,2 \%)$ & $152(50,5 \%)$ & $56(18,6 \%)$ & $14(4,7 \%)$ \\
\hline $\begin{array}{l}\text { Tenho pensado menos no } \\
\text { meu trabalho e o realizo de } \\
\text { forma mecânica }\end{array}$ & $64(21,3 \%)$ & $164(54,5 \%)$ & $62(20,6 \%)$ & $11(3,7 \%)$ \\
\hline $\begin{array}{l}\text { Considero que meu trabalho } \\
\text { é um desafio positivo }\end{array}$ & $3(1 \%)$ & $45(15 \%)$ & $192(63,8 \%)$ & $61(20,3 \%)$ \\
\hline $\begin{array}{l}\text { Sinto-me desligado do meu } \\
\text { trabalho }\end{array}$ & $70(23,3 \%)$ & $163(54,2 \%)$ & $59(19,6 \%)$ & $9(3 \%)$ \\
\hline $\begin{array}{l}\text { Este é o único trabalho que } \\
\text { me imagino fazendo }\end{array}$ & $29(9,6 \%)$ & $133(44,2 \%)$ & $99(32,9 \%)$ & $40(13,3 \%)$ \\
\hline $\begin{array}{l}\text { Sinto-me cada vez mais } \\
\text { empenhado no meu trabalho }\end{array}$ & $12(4 \%)$ & $104(34,6 \%)$ & $158(52,5 \%)$ & $27(9 \%)$ \\
\hline $\begin{array}{l}\text { Às vezes, sinto-me farto das } \\
\text { minhas tarefas }\end{array}$ & $15(5 \%)$ & $88(29,2 \%)$ & $168(55,8 \%)$ & $30(10 \%)$ \\
\hline
\end{tabular}


Através de um corte dicotômico, separamos os profissionais alocados no Estado de São Paulo, cujo estado apresenta o maior IDH do Brasil, dos profissionais que exercem a profissão no restante dos estados brasileiros. O objetivo desta separação foi o de verificar se o IDH poderia ser um fator que interferisse na presença ou não da SB. Nos dados obtidos não encontramos associação significativa entre a SB e o IDH $(p=0,052)$. Entretanto, devido a significância estatística observada, novos estudos poderão ser realizados para verificar a importância desta variável em relação a SB. (Tabela 4)

Tabela 4 - Estudo de associação entre a SB e o IDHA

\begin{tabular}{cccccc}
\hline & \multicolumn{2}{c}{ Brasil } & & \\
\cline { 2 - 3 } Final Burnout & Outro Estado & SP & & Total & $P$ \\
\hline Com Burnout & 64 & 74 & & \\
Sem Burnout & 58 & 106 & 138 & 0,052 \\
Total & 122 & 180 & 302 & \\
\hline
\end{tabular}

No presente estudo, encontramos a associação significativa entre a Síndrome de Burnout e a faixa etária $(\chi 2=10.7, p=0,03)$, sendo mais acometidos os profissionais da faixa etária de 20 à 30 anos, nos profissionais que trabalham exclusivamente no setor privado $(\chi 2=7.29, \mathrm{p}=$ 0.026), dos odontólogos que relataram ter os conhecimentos satisfatórios sobre as formas de proteção ao SARS-CoV-2 $(\chi 2=11.4, \mathrm{p}=0.003)$, dos cirurgiões-dentistas que suspenderam totalmente o atendimento durante a pandemia $\left(\chi^{2}=6.12, \mathrm{p}=0.047\right)$, daqueles que tem medo de serem responsáveis por transmitir o vírus a seus familiares $(\chi 2=9.42, \mathrm{p}=0.002)$, dos profissionais que não foram contaminados ainda $(\chi 2=13.2, p=<0.001)$, daqueles que tem medo de se contaminar durante a execução do seu trabalho profissional $(\chi 2=8.16, p=0.004)$ e dos odontólogos que relataram terem medo de morrer pela contágio do SARS-CoV-2 ( $\chi 2=$ $22,9, \mathrm{p}<0,001$. Já em relação ao nível de atuação clínica $(\chi 2=1.7, \mathrm{p}=0.192)$ e ao gênero ( $\chi 2$ $=1.15, \mathrm{p}=0.284)$ não foram encontradas associações significativas. (Tabela 5) 
Tabela 5 - Estudo de associação da síndrome de Burnout com as variáveis de interesse

\begin{tabular}{|c|c|c|c|c|c|c|}
\hline \multirow[t]{2}{*}{ Variáveis } & & Classificação & Burnout & Total & \multirow[b]{2}{*}{$X^{2}$} & \multirow[b]{2}{*}{$P$} \\
\hline & & Presente & Ausente & & & \\
\hline \multirow[t]{2}{*}{ Gênero } & Feminino & 102 & 112 & 214 & 1.15 & 0.284 \\
\hline & Masculino & 36 & 52 & 88 & & \\
\hline Faixa Etária & 20 à 30 & $33^{*}$ & 21 & 54 & 10.7 & $0.003 *$ \\
\hline \multirow[t]{4}{*}{ (Anos) } & 31 à 40 & 33 & 32 & 65 & & \\
\hline & 41 à 50 & 47 & 65 & 112 & & \\
\hline & 51 à 60 & 23 & 38 & 61 & & \\
\hline & $>61$ & 2 & 8 & 10 & & \\
\hline \multirow{3}{*}{$\begin{array}{l}\text { Setor de Atividade } \\
\text { de Trabalho. }\end{array}$} & Ambos & 31 & 26 & 57 & & \\
\hline & S. Privado & $80 *$ & 119 & 199 & 7.29 & $0,002 *$ \\
\hline & S. Público & 27 & 19 & 46 & & \\
\hline \multirow[t]{2}{*}{ Atuação Clínica } & Clí. Geral & 65 & 65 & 130 & 1,7 & 0,192 \\
\hline & Especialista & 73 & 99 & 172 & & \\
\hline Odontólogo com & Não & $82 *$ & 129 & 211 & 13,2 & $<0,001^{*}$ \\
\hline SARS-CoV-2 + & Sim & 56 & 35 & 91 & & \\
\hline Medo de Transmitir & Não & 10 & 32 & 42 & & \\
\hline o vírus a familiares & Sim & 128 & 132 & 260 & 9,42 & $0,002 *$ \\
\hline Medo de morrer & Às vezes & 28 & 67 & 95 & & \\
\hline \multirow[t]{2}{*}{ Pelo SARS-CoV-2 } & Não & 15 & 29 & 44 & & \\
\hline & Sim & $95^{*}$ & 68 & 163 & 22,9 & $<0,001^{*}$ \\
\hline Conhecimentos & Não & 23 & 12 & 35 & & \\
\hline \multirow[t]{2}{*}{ protetivos ao vírus } & Sim & $75^{*}$ & 118 & 193 & 11,4 & $0,003 *$ \\
\hline & Talvez & 40 & 34 & 74 & & \\
\hline Medo contaminação & Não & 24 & 52 & 76 & & \\
\hline no trabalho & $\operatorname{Sim}$ & 114 & 112 & 226 & 8,16 & $0,004 *$ \\
\hline Suspendeu trabalho & Não & 25 & 33 & 58 & & \\
\hline \multirow[t]{2}{*}{ durante a pandemia } & $\operatorname{Sim}$ & $25^{*}$ & 14 & 39 & 6,12 & $0,047 *$ \\
\hline & Temporar. & 88 & 117 & 205 & & \\
\hline
\end{tabular}




\section{4- Discussão}

Este estudo é inovador, uma vez que contribui com as evidências científicas ao abordar o impacto da pandemia de SAR-CoV-2 e a Síndrome de Burnout em cirurgiões-dentistas. Nossos principais resultados mostraram que o medo de transmitir a COVID19 para família e o medo de se contaminar durante o atendimento odontológico foram significativos no grupo de indivíduos com SB. Adicionalmente, no GB mais de 80\% suspendeu em algum momento o atendimento odontológico, embora $63,8 \%$ acreditassem ter conhecimento suficiente para proteção contra a COVID19, 85,4\% deles relataram ter ou já terem tido medo de morrer ao contrair a doença.

Vários estudos têm apontado que as profissões de saúde têm sido acometidas cada vez mais pela Síndrome de Burnout. ${ }^{15-17}$ Entretanto, poucos são estudos que relacionados à Odontologia $^{20,24-28}$ e a questão relacionada ao stress intrinsicamente associada à Síndrome de Burnout frente à pandemia de SARS-CoV-2. A proximidade entre cirurgião-dentista e paciente, sendo que o último sem o uso de máscara, aumenta a chance do profissional se contaminar nas condições clínicas, alterando a saúde emocional também.

A investigação de informações sobre as condições emocionais desses profissionais deve ser identificada e diagnosticada precocemente, proporcionando que medidas protetivas sejam elaboradas com a finalidade da diminuição do impacto da pandemia e da SB nesses profissionais. Através da aplicação do questionário de OLBI, ficou evidenciado o grau elevado de profissionais com exaustão ou distanciamento do trabalho. A Síndrome de Burnout foi identificada em quase a metade dos profissionais (46,35\%), achados que vão ao encontro dos dados de CAMPOS e SGUAREZI que encontraram 48,3\% e 51,4\%, respectivamente. ${ }^{24,30}$ Entretanto, o presente trabalho teve a participação de profissionais que trabalham tanto no setor público como no privado, diferentemente desses dois estudos que foram compostos exclusivamente por profissionais do setor público. E justamente nos profissionais pertencentes ao setor privado encontramos associação significativa com a SB $(p=0,026)$. Essa associação pode estar relacionada ao fato que devido à pandemia os profissionais do setor público suspenderam os tratamentos eletivos, ficando restritos aos atendimentos de emergência, o que, de certa forma, os protegem de uma possível contaminação durante o trabalho. Já os profissionais do setor privado, apesar do receio do contágio pelo SARS-CoV-2, precisaram retornar ao trabalho precocemente para poderem manter a sua fonte de subsistência e honrarem os compromissos financeiros assumidos anteriormente a pandemia. Outro fator de queda no rendimento financeiro e consequentemente, gerador de impacto emocional no profissional 
privado relacionado a pandemia, foi o medo dos pacientes de retornarem aos tratamentos. Preocupados com a possibilidade de uma contaminação em um consultório odontológico, muitos pacientes cancelaram seus tratamentos, provocando uma diminuição dos ganhos financeiros dos odontólogos.

Em relação ao sexo do profissional, não foi encontrada associação significativa com a Síndrome de Burnout, reforçando os achados de MURTOMAA. ${ }^{16}$ Por outro lado, um estudo encontrou associação positiva ao sexo feminino, sugerindo que a possibilidade de muitas mulheres se dedicarem a jornadas profissionais e familiares possam ter elevado o nível de estresse dessas dentistas. ${ }^{26}$ Estudos futuros poderão ser conduzidos para verificar os possíveis fatores de associação ligados ao sexo.

Em relação à idade do profissional, encontramos associação positiva com a Síndrome de Burnout, sendo que a faixa etária de 20 a 30 anos foi a mais significativa. Nossos dados corroboram com os de FLORES LOZANO referente aos jovens ingressantes no mercado de trabalho. Os autores sugeriram que a expectativa e receios gerados no início da jornada profissional, aliados a dificuldade de inserção profissional podem ter contribuído para intensificar os problemas nos egressos ao mercado de trabalho. ${ }^{27}$ Já um outro estudo, não encontrou associação significativa relacionado a SB e a idade. A inexperiência profissional, aliada a exposição ao SARS-CoV-2, parece causar maior impacto emocional nesses profissionais que atuam em clínicas privadas.

Um ponto a ser analisado é a jornada de trabalho do profissional, sendo que não foi encontrada associação significativa com a presença da Síndrome de Burnout. Entretanto, a jornada entre 31-40 horas semanais, apresentou o maior percentual de cirurgiões-dentistas com SB (Tabela 4). A associação significativa entre profissionais com jornadas de trabalho mais elevadas foi identificada em uma pesquisa realizada no serviço publico britânico, sugerindo que o aumento do número de pacientes atendidos diariamente e consequentemente à diminuição do tempo disponível para a realização de atividades pessoais e de lazer tinham impactado a saúde emocional desses profissionais. ${ }^{25} \mathrm{O}$ nível de profissionalização, entre clínicos gerais e especialistas, não apresentou associação com a SB, também encontrado em outro estudo. ${ }^{16}$ No nosso estudo vale ressaltar que a exposição ao SARS-CoV-2 de uma certa forma tornou-se uma preocupação geral independentemente da área de atuação. Em uma revisão sistemática recente realizada por nosso grupo de pesquisa, propôs-se um protocolo clínico adotando-se as seguintes medidas: procedimentos antes das consultas, manuseio correto da área operatória e uso de EPI correto no sentido de reduzir o risco biológico. Os principais riscos biológicos, da COVID-19 encontrados, foram infecção e transmissão horizontal. Os autores destacaram a importância do 
cirurgião-dentista desempenhar um importante papel na prevenção e na interrupção da cadeia de transmissão do coronavírus 2 da síndrome respiratória aguda grave. ${ }^{31}$

Dentre os profissionais de saúde, os odontólogos têm sido altamente expostos à infecção pelo SARS-CoV-2, como mencionado anteriormente. Esses profissionais realizam rotineiramente os procedimentos com instrumentos que geram aerossóis (pequenas partículas), que podem ser inalados no ambiente de trabalho, expondo tanto o clínico quanto o paciente à infecção. Os profissionais da odontologia devem proteger os pacientes da propagação de todas as doenças infecciosas, adotando práticas seguras no desempenho de seu trabalho e tornando os procedimentos odontológicos sem riscos. ${ }^{33}$

Em relação as variáveis relacionadas à pandemia, encontramos associações positivas entre a Síndrome de Burnout nos odontólogos que testaram positivo ao SARS-CoV-2 ( $\mathrm{p}=0,003)$, nos profissionais que tem medo de transmitir o vírus a seus familiares $(\mathrm{p}=0,001)$, nos que relataram ter conhecimentos protetivos suficientes $(p=0,001)$, como também naqueles que tem medo de se contaminar durante o seu exercício clínico $(\mathrm{p}=0,001)$ e nos odontólogos que suspenderam o atendimento clínico durante a pandemia $(\mathrm{p}=0,047)$. Esses resultados trazem uma preocupação e uma evidência de que a pandemia de SARS-CoV-2 é um fator adicional e importante nos fatores de risco a Síndrome de Burnout. Os resultados encontrados devem ser levados em conta na elaboração de protocolos preventivos para os profissionais de odontologia afim de que estas novas variáveis não contribuam para um agravamento dos índices de profissionais acometidos pela SB. Novas pesquisas devem ser realizadas com o intuito de elucidar as causas e consequências de cada variável na vida profissional do odontólogo, bem como nas formas de minimizar ou preveni-la.

O impacto emocional se inicia previamente a ocorrência da Síndrome de Burnout. A SB pode levar ao comprometimento da saúde do trabalhador, bem como refletir negativamente sobre o ambiente de trabalho, resultando em distanciamento, diminuição da produtividade e na qualidade do serviço executado e até mesmo em alguns casos, a incapacidade total de trabalho. O presente estudo demonstrou que menos de $1 / 4$ da amostra $(n=69 ; 22,84 \%)$ se apresentavam sem alterações emocionais. Por outro lado, entre o distanciamento $(n=46 ; 15,23 \%)$ somado a exaustão ao trabalho $(n=49 ; 16,22 \%)$ totalizou-se $1 / 3$ da amostra. Esses achados sinalizam o risco que o cirurgião-dentista corre de sofrer alterações emocionais, demonstrando que quase $80 \%$ pode sofre algum abalo.

Silva et al (2016) sugeriram algumas estratégias de intervenção para a prevenção e tratamento da Síndrome de Burnout que foram agrupadas em três categorias: 1) Estratégias 
individuais: fazendo uso do treinamento na solução dos problemas, do aumento da assertividade, e de formas de ação com finalidade de utilizar o tempo de maneira eficaz. 2) Estratégias grupais: são medidas que devem ser tomadas por toda a equipe de trabalho visando a busca pela excelência, como o uso do apoio social de todos os integrantes da equipe, bem como dos supervisores. 3) Estratégias Organizacionais, utilizando-se de ações que maximizem a organização do trabalho, bem como o de desenvolver programas de prevenção dirigidos para melhorar a atmosfera e o clima da organização. ${ }^{33}$ Devemos também contemplar as questões que geram desgaste na saúde mental do trabalhador: limitacões técnicas, pessoais e materiais; a alta demanda de atendimento; a falta de tempo para atividades de lazer ou familiar; o desrespeito de alguns pacientes insatisfeitos no caso do serviço púbico e, em especial, a baixa remuneração, seja dos profissionais concursados ou daqueles que atendem pacientes oriundos de planos ou cooperativas de saúde. Esses fatores, somados às pressões organizacionais e vivenciados diariamente, geram uma sobrecarga emocional que pode interferir inclusive na relação dos profissionais com os pacientes, na sua produtividade e na excelência do trabalho.

Por se tratar de uma doença recente, não há na literatura nenhum estudo que tenha investigado a associação da SB com a COVID19 em cirurgiões-dentistas. Porém, os resultados positivos a esta associação revelaram que os profissionais estão com dificuldades emocionais atreladas a pandemia e este fator pode ser um adicional importante ao agravamento do número de odontólogos acometidos pela Síndrome de Burnout. Como limitação deste estudo deve-se considerar o modelo transversal que impossibilita o estabelecimento de relações causais entre as variáveis, bem como o acompanhamento destes profissionais durante a evolução da pandemia. Como pontos fortes destaca-se que somente cerca de um quinto da amostra não sofreu alterações de ordem mental frente à pandemia e a quase a metade já apresentavam a síndrome de Burnout. Dessa forma, podemos ter um importante registro do momento emocional destes profissionais afim de que medidas possam ser efetivadas com o intuito preventivo à Síndrome de Burnout, principalmente associado a uma situação crítica como a da pandemia de SARS-CoV-2 que não há previsão para a sua remissão.

\section{3- Conclusão}

Os achados do presente estudo evidenciam que houve impacto da pandemia de COVID-19 na saúde emocional e na ocorrência da Síndrome de Burnout em cirurgiões-dentistas, especialmente em relação ao medo de contaminar a família, medo de se infectar, medo de morrer e ao profissional estabelecido no setor privado. A presença da SB em quase metade dos profissionais esteve fortemente associada as variáveis relacionadas ao SARS-CoV-2. 


\section{Referências Bibliográficas:}

1- Li Y, Xia L. Coronavirus Disease 2019 (COVID-19): Role of chest CT in diagnosis and management [Epub ahead of print]. AJR Am J Roent- genol. 2020:1-7.

2- Zu, Z.Y.; Jiang, M.D.; Xu, P.P.; Chen, W.; Ni, Q.Q.; Lu, G.M.; Zhang, L.J. Coronavirus Disease 2019 (COVID-19): A Perspective from China. Radiology 2020, 200490.

3- Ministério da Saúde. Brasil. 2020. https://www.unasus.gov.br/noticia/organizacao-

a. mundial-de-saude-declara-pandemia-de-coronavirus, acessado em 28/05/2020.

4- Peng X, Xu X, Li Y, Cheng L, Zhou X, Ren B. Transmission routes of 2019-nCoV and controls in dental practice. Int J Oral Sci. 2020;12(1):9.

5- Huang C, Wang Y, Li X, et al. Clinical features of patients infect- ed with 2019 novel coronavirus in Wuhan, China. Lancet. 2020;395(10223):497-506.

6- Khurshid, Z.; Asiri, F.Y.I.; Wadaani, H. Al Human Saliva: Non-Invasive Fluid for Detecting Novel Coronavirus (2019-nCoV). Int. J. Environ. Res. Public Health 2020, 17,2225 .

7- Wu, P.; Hao, X.; Lau, E.H.Y.; Wong, J.Y.; Leung, K.S.M.; Wu, J.T.; Cowling, B.J.; Leung, G.M. Real-time tentative assessment of the epidemiological characteristics of novel coronavirus infections in Wuhan, China, as at 22 January 2020. Euro Surveill. $2020,25,1-6$.

8- Chen N, Zhou M, Dong X, et al. Epidemiological and clinical characteristics of 99 cases of 2019 novel coronavirus pneumonia in Wuhan, China: A descriptive study. Lancet. 2020;395(10223):507-513.

9- Emary KRW, Golubchik T, Aley PK, Ariani CV, Angus B, Bibi S, et al. COVID-19 Genomics UK consortium; AMPHEUS Project; Oxford COVID-19 Vaccine Trial Group. Efficacy of ChAdOx1 nCoV-19 (AZD1222) vaccine against SARS-CoV-2 variant of concern 202012/01 (B.1.1.7): an exploratory analysis of a randomised controlled trial. Lancet. 2021 Apr 10;397(10282):1351-1362. doi: 10.1016/S01406736(21)00628-0. Epub 2021 Mar 30. PMID: 33798499; PMCID: PMC8009612

10- Bin SY, Heo JY, Song MS, et al. Environmental contamination and viral shedding in MERS patients during MERS-CoV outbreak in South Korea. Clin Infect Dis. 2016;62(6):755-760.

11-Ather, A.; Patel, B.; Ruparel, N.B.; Diogenes, A.; Hargreaves, K.M. Coronavirus Disease 19 (COVID-19): Implications for Clinical Dental Care. J. Endod. 2020. 
12- Fazel, M.; Hoagwood, K.; Stephan, S.; Ford, T. Mental health interventions in schools in high-income countries. Lancet Psychiatry 2014, 1, 377-387.

13- Vicente CS, Oliveira RA, Maroco J. Análise fatorial do Inventário de Burnout de Maslach (MBI-HSS) em profissionais portugueses. Psicologia, Saúde \& Doenças 2013; 14(1)152167.

14- Maslach C, Jackson SE. Maslach burnout inventory manual. Palo Alto: Consulting Psychologist Press; 1986.

15-Te Brake H, Smits N, Wicherts JM, Gorter RC, Hoogstraten J. Burnout development among dentists: a longitudinal study. Eur J Oral Sci. 2008; 116: 545-51.

16- Murtomaa H, Haavio-Mannila E, Kandolin I. Burnout and its causes in Finnish dentists. Community Dent Oral Epidemiol. 1990; 18: 208-12.

17-Demerouti E, Bakker AB, Nachreiner F, Schaufeli WB. The job demands-resources model of burnout. J Appl Psychol. 2001; 86: 499-512.

18- Vandenbroucke JP, Von Elm E, Altman DG, Gøtzsche PC, Mulrow CD, Pocock SJ, et al. Strengthening the reporting of observational studies in epidemiology (STROBE): explanation and elaboration. PLoS Medicine. 2007;4:e297. doi: 10.1371/journal.pmed.0040297

19- Coluci, MZO, Alexandre, NMC , \& Milani, . (2015). Construção de instrumentos de medida na área da saúde. Ciência \& Saúde Coletiva, 20(3), 925936. https://doi.org/10.1590/1413-81232015203.04332013

20- Demerouti, E. et al. The convergent validity of two burnout instruments - A multitraitmultimethod analysis. European Journal of Psychological Assessment, v. 19, n. 1, p. 12-23, 2003. ISSN 1015-5759

21- Peterson U, Demerouti E, Bergstrom G, Asbrrg M, Nygren A. Work characteristics and sickness absence in burnout and non burnout groups: a study of swedish health care workers. Int J Stress Manag. 2008; 15: 153-72.

22-Kline RB. Principles and practice of structural equation modeling. The Guilford Press; New York: 1998.

23- Landis JR, Koch GG. The measurement of observer agreement for categorical data. 1977. Biometrics 33:159

24- Campos JADB, Trotta OST, Bonafe FSS, Maroco J. Burnout em dentistas do serviço público: ter ou não ter, eis a questão! Rev Odontol UNESP. 2010; 39(2): 109-114. 
25- Osborne D, Croucher, R. Levels of burnout in general dental practitioners in the southeast of England. Br. Dent. J., London, v.177, n. 10, p.372-377, Nov. 1994.

26- Cooper CL, Watts J, Kelly M. Occupational stress amongst general practice dentists. J. Occup. Psychol., London, v.61, n. 1, p. 163-174, 1988.

27- Flórez Lozano JA. Síndrome de "Estar Quemado". Barcelona: Edika-Méd; 1994.

28-Zucoloto ML,Jordani PC, Bonafé FS, et al. Síndrome de Burnout em CirurgiõesDentistas com Diferentes AtuaçõesProfissionais. Psychology, Community \& Health. 2014;3(2):62-72

29- Lima FD, Buunk AP, Araújo MBJ, Chaves JGM, Muniz DLO, Queiroz LB. Síndrome de Burnout em residentes da Universidade Federal de Uberlândia - 2004. Rev. bras. educ. med. 2007; 31 (2): 137-146.

30- Sguarezi, D. Avaliacao da Síndrome de Burnout em cirurgiões-dentistas no munícipio de Cuiabá, Estado do Mato Grosso, Brasil. 2014. 42 f. Dissertação- UNICAMP, Faculdade de Odontologia de Piracicaba, Piracicaba, SP. [Acesso em 26/01/2021]. Disponível em: http://www.repositorio.unicamp.br/handle/REPOSIP/289162>

31-Castro MS, Castilho AVSS, Azevedo-Silva LJ, Santos LF, Orenha ES, Sales-Peres SHC "Coronavirus Disease 2019 Biological Risk and Clinical Care Protocol in Dentistry: A Systematic Review". Acta Scientific Dental Sciences 5.5 (2021): 28-43.

32- Silva ABN, Maximino DAFM, Souto CGV, Virgínio NA. Síndrome de Burnout em profissionais de enfermagem na unidade de terapia intensiva. Rev. Ciênc. Saúde Nova Esperança, v.14, n.1, p.79-86, 2016.

33- Peditto M., et al. "Dentistry during the COVID-19 Epidemic: An Italian Workflow for the Management of Dental Practice". 20. International Journal of Environmental Research and Public Health 17.3325 (2020). 
Figura 1 - Fluxograma do sistema de inclusão nos grupos, Grupo Sem Burnout (GC) e Grupo com Burnout (GB 

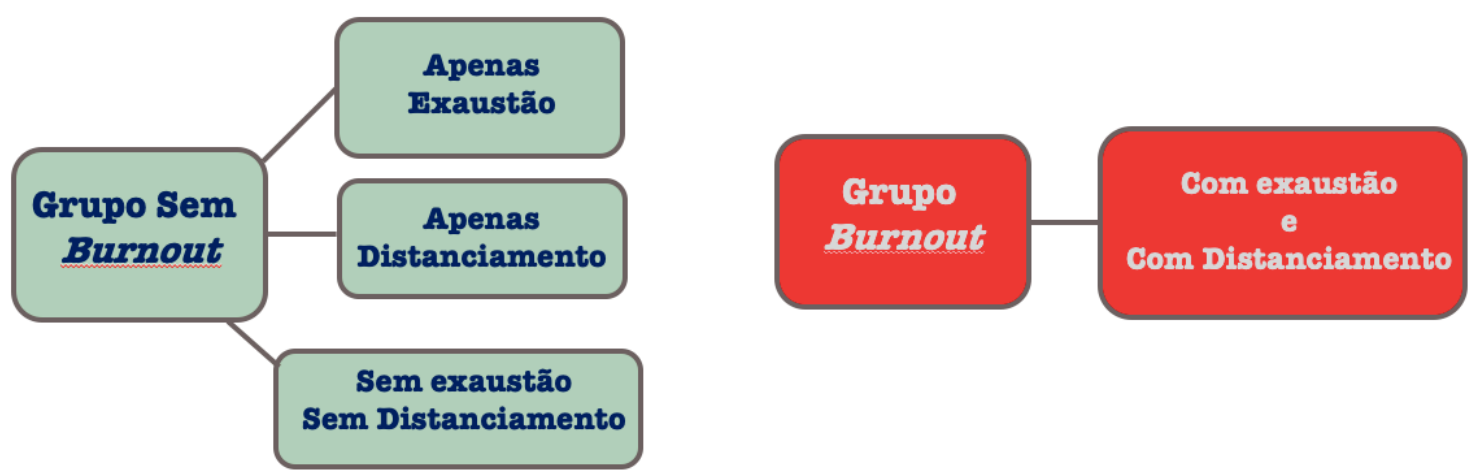

Figura 1 





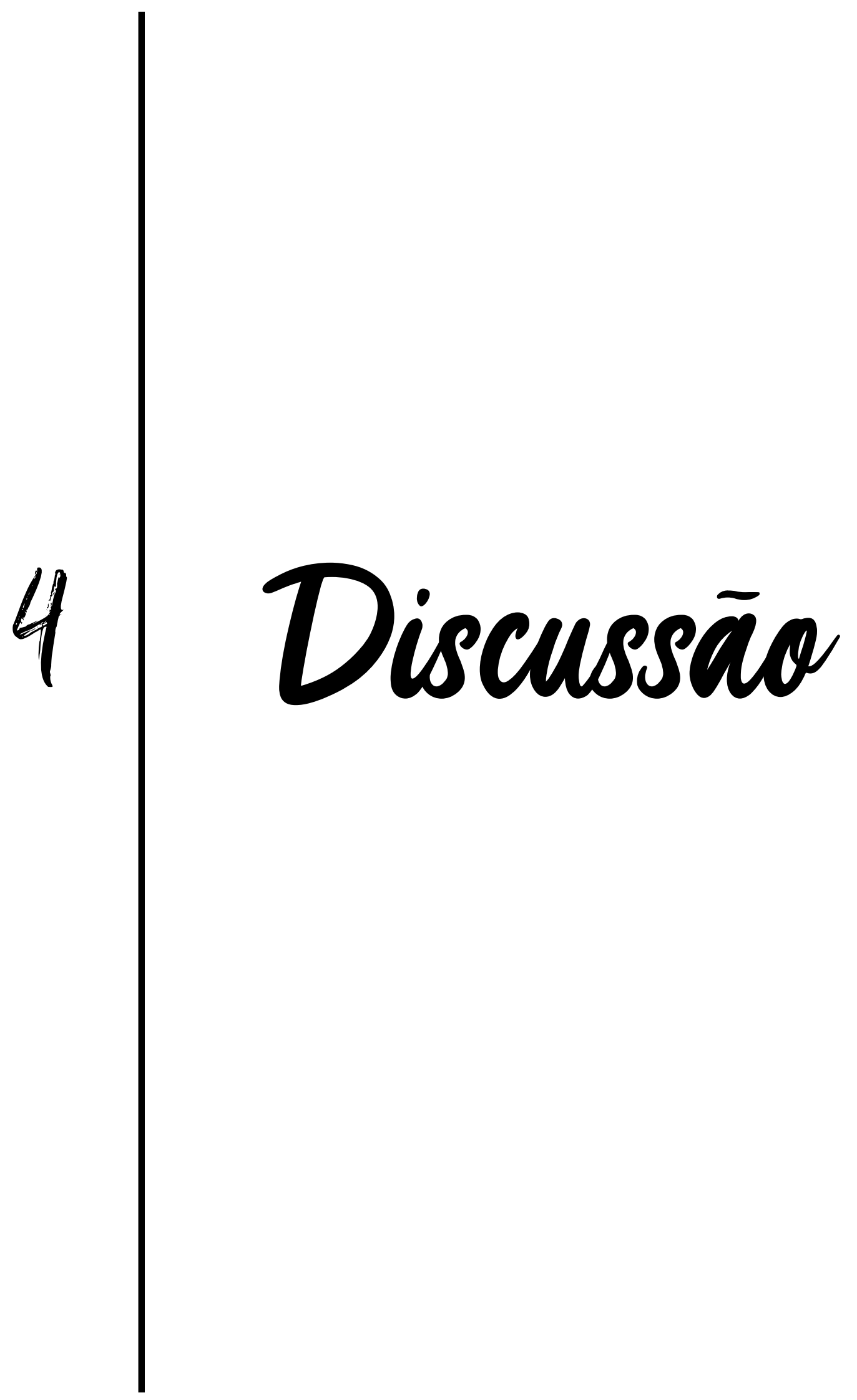







\section{Discussão}

Os consultórios odontológicos sempre seguiram rígidas regras de controle da biossegurança para controle de infecções devido a presença de fluidos como sangue e saliva em seu campo de trabalho. ${ }^{1}$ Em dezembro de 2019, foi identificada uma nova cepa do Coronavírus que por uma mutação ocorrida na proteína Spike viral se tornou capaz de infectar seres humanos. ${ }^{2}$ Devido a sua alta capacidade de transmissibilidade e patogenicidade, a OMS decretou estado de pandemia causado pelo SARS-CoV-2. ${ }^{3}$ Em razão da gravidade da doença que poderia ocasionar distúrbios respiratórios graves, como até mesmo levar o infectado ao óbito, ${ }^{4,5}$ muitos cirurgiões-dentistas por recomendações dos Conselhos de Odontologia suspenderam os atendimentos eletivos. Diversos estudos começaram a ser realizados com a finalidade de desenvolver métodos protetivos e sugerir EPIs eficientes que pudessem neutralizar as formas de contágio e consequentemente, trazer segurança durante o trabalho para as equipes de saúde e também aos pacientes atendidos. ${ }^{6-10}$

Uma das formas de diminuição da transmissibilidade sugeridas pela OMS e adotadas por muitos países foi o isolamento social. Tal isolamento, quando realizado por tempo longo pode gerar consequências econômicas e psicológicas graves. ${ }^{11}$ Aliado ao stress causado pelo isolamento social, o medo gerado por estar mais exposto a uma contaminação ou de se tornar o vetor que pudesse disseminar o vírus para os seus familiares, o surgimento de novas cepas com maior capacidade de transmissibilidade, proporcionam que o profissional de saúde tenha um comprometimento psicológico maior que qualquer outra profissão durante a pandemia. ${ }^{12,13}$

Em relação as percepções do odontólogo frente à pandemia, nossos estudos encontraram que $29,9 \%$ da amostra já haviam testado positivo ao SARS-CoV-2, 85,5\% deles tem medo de morrer pelas consequências da manifestação viral, $86 \%$ tem medo de se contaminarem e transmitirem a seus familiares e que $80,7 \%$ dos profissionais suspenderam a atividade profissional por algum tempo durante à pandemia.

Numa rotina diária sem a presença de uma pandemia, os odontólogos já estavam entre as profissões mais afetadas pela Síndrome de Burnout. A SB é caracterizada pelo excesso de trabalho, bem como pelo estresse contínuo e prolongado que pode levar o profissional a depressão e ao distanciamento das suas atividades laborais. ${ }^{18}$ A piora na qualidade dos trabalhos prestados pelo cirurgião-dentista, bem como todo a destruição emocional e da autoestima dos profissionais estão entre as principais consequências da SB. ${ }^{18}$ Os primeiros estudos de Burnout foram desenvolvidos por Maslach e foram realizados em três etapas; iniciando com entrevistas e observação de campo; a segunda fase através da criação de escalas para a mensuração da 
síndrome; e a terceira por meio de estudos longitudinais, método esse que foi denominado de MBI-GS. ${ }^{18}$

Em 1999, Demerouti et al contestaram a utilização do método proposto devido a possibilidade de enviesamento das respostas por não conterem elementos que avaliassem os aspectos físicos e cognitivos na dimensão exaustão. ${ }^{19}$ Dessa forma, Demerouti et al propuseram uma nova escala de mensuração da SB denominada de Oldenburg Burnout Inventory (OLBI), o qual foi dividido em dois níveis de avaliação: exaustão e desligamento do trabalho. ${ }^{19} \mathrm{Na}$ dimensão exaustão é avaliada o nível de pressão psicológica, física e afetiva relacionadas as consequências do acúmulo dos fatores pressão física e emocional associadas as exigências e condições de trabalho. Já na dimensão desligamento, são avaliados especificamente a questão relacionada a identificação do profissional com o seu trabalho, bem como a intenção e vontade de o continuar exercendo. ${ }^{19}$

No Brasil poucos trabalhos foram desenvolvidos para mensurar a SB nos cirurgiõesdentistas. Em nosso estudo, 46,3\% dos profissionais apresentaram a Síndrome de Burnout. Esses resultados vão de encontro aos resultados encontrados por Campos e Sguarezi. ${ }^{20,21}$ Entretanto, nesses estudos tiveram como amostra apenas profissionais que atuavam no setor público, diferentemente de nosso trabalho que avaliou os cirurgiões-dentistas de ambos os setores. Na análise de associação entre a SB e as percepções dos profissionais à pandemia de SARS-CoV-2, encontramos associação positiva com o setor de trabalho nos profissionais que atuam exclusivamente no setor privado $(\mathrm{p}=0,004)$. Este resultado está associado ao fato de que tais profissionais, devido o trabalho em consultório particular ser sua única e exclusiva fonte de renda familiar, tiveram que enfrentar o medo da contaminação e das complicações ocasionadas pelo SARS-CoV-2 para manter a subsistência familiar e os compromissos financeiros assumidos previamente à pandemia, enquanto que os profissionais estabelecidos no setor público suspenderam totalmente a suas atividades no primeiro momento, só retornando ao trabalho em casos exclusivos de emergência, bem como que tal profissional não teve comprometimento financeiro, haja visto que mesmo não exercendo suas atividades plenamente, os seus honorários foram preservados. Todas as outras variáveis de percepção dos profissionais relacionadas à pandemia também apresentaram associação com a SB; cirurgiões-dentistas que testaram positivo ao SARS-CoV-2 ( $<<0.001)$; medo de transmitir o vírus a seus familiares $(p=0,002)$; medo de morrer pela contaminação viral $(p<0,001)$; dos profissionais que possuem conhecimentos protetivos suficientes $(\mathrm{p}=0,003)$; dos que tem medo de se contaminar durante o 
trabalho $(\mathrm{p}=0,004)$; e dos profissionais que suspenderam as atividades durante à pandemia $(p=0,047)$.

Por se tratar de uma pandemia nunca antes vivida na vida moderna, nenhum trabalho foi encontrado que tenha realizado um estudo relacionando a Síndrome de Burnout com as consequências físicas e psicológicas acometidas pelo o cirurgião-dentista pelo COVID-19. Este estudo, por seu pioneirismo, pode ajudar para que medidas possam ser elaboradas e introduzidas na rotina do profissional com intuito de identificar e prevenir que as consequências da pandemia possam aumentar a carga psicológica dos cirurgiões-dentistas que, devido a suas características de trabalho, já estão tão expostos à instalação da Síndrome de Burnout. 





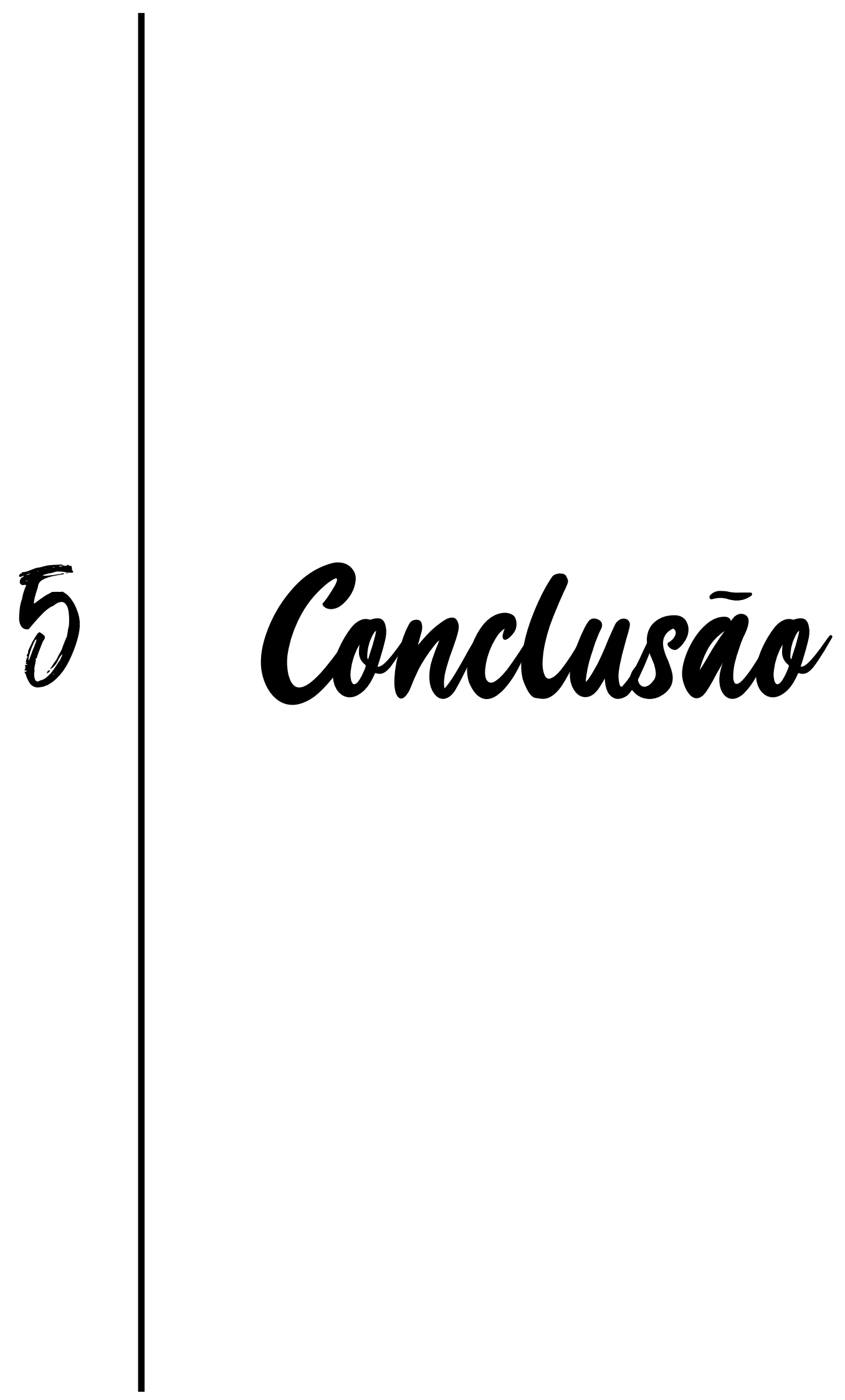







\section{Conclusão}

O presente estudo encontrou que os cirurgiões-dentistas tiveram um grande impacto emocional causado pela pandemia de SARS-CoV-2 e que aproximadamente metade da amostra apresentava a Síndrome de Burnout. Todas as variáveis relacionadas à pandemia apresentaram associação positiva com a SB. 





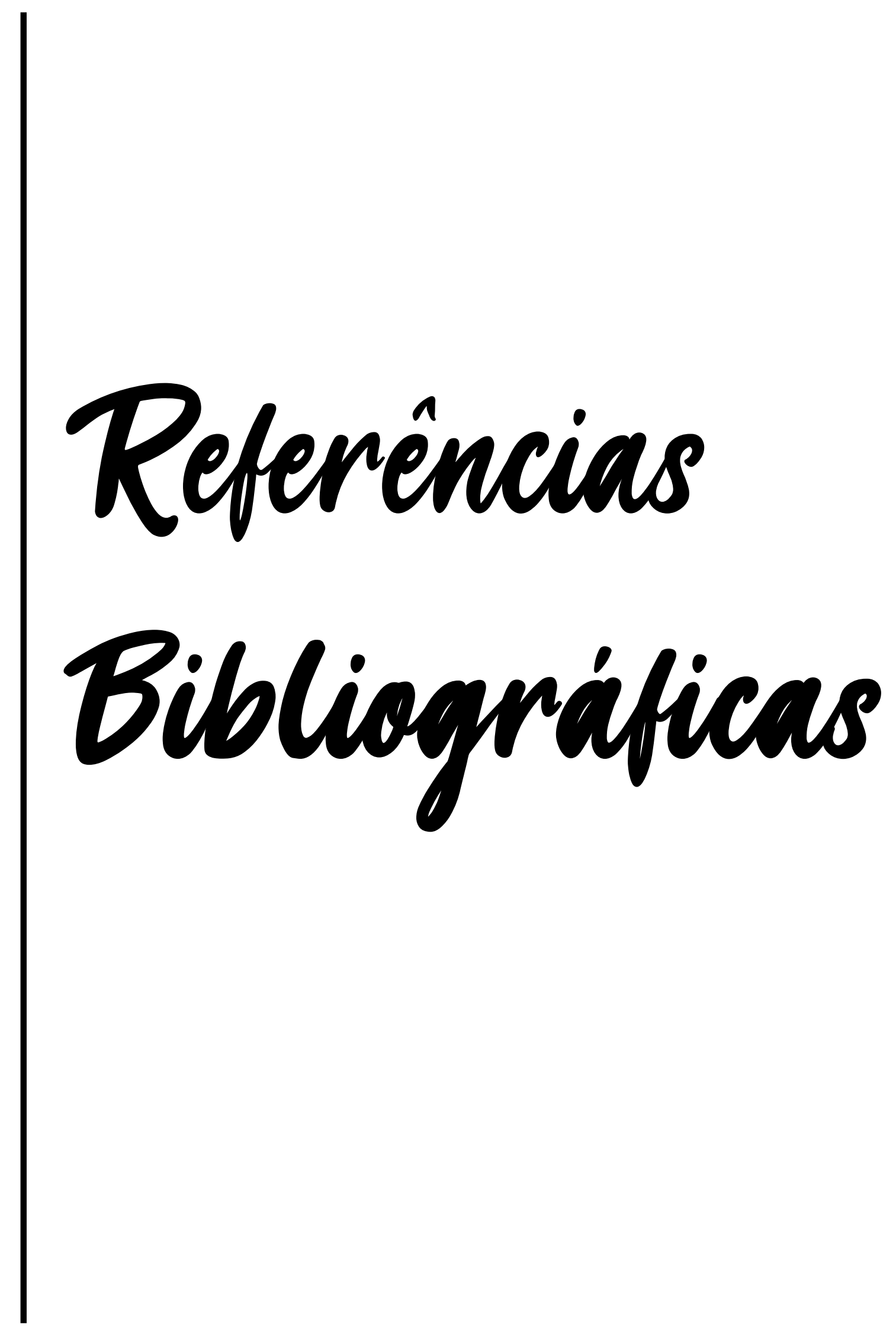







\section{Referências Bibliográficas:}

1- Krieger D, Bueno R, Gabardo MCL. Perspectivas de biossegurança em odontologia. Rev Gestão Saúde. 2010;1(2):1-10.

2- Lu R, Zhao X, Li J, et al. Genomic characterisation and epidemiology of 2019 novel coronavirus: Implications for virus origins and receptor binding. Lancet. 2020; 395:565574.

3- Holshue ML, DeBolt C, Lindquist S, et al. First case of 2019 novel coronavirus in the United States. N Engl J Med. 2020; 382:929-936.

4- Huang, N., Pérez, P., Kato, T. et al. SARS-CoV-2 infection of the oral cavity and saliva. Nat Med (2021). https://doi.org/10.1038/s41591-021-01296-8

5- Azzi L, Carcano G, Gianfagna F, Grossi P, Gasperina DD, Genoni A, Fasano M, Sessa F, Tettamanti L, Carinci F, Maurino V, Rossi A, Tagliabue A, Baj A. Saliva is a reliable tool to detect SARS-CoV-2. J Infect. 2020 Jul;81(1):e45-e50. doi: 10.1016/j.jinf.2020.04.005. Epub 2020 Apr 14. PMID: 32298676; PMCID: PMC7194805.

6- Meng L., Hua F., Bian Z. Doença por coronavírus 2019 (COVID-19): Desafios emergentes e futuros para medicina dentária e oral. J Dent Res.; 99 (5): 481-487. Maio, 2020.

7- Fallahi HR. et al. Being a front-line dentist during the Covid-19 pandemic: a literature review. Maxillofac Plast Reconstr Surg. 24;42(1):12. Abril, 2020.

8- Stadnytskyi V. et al. A vida útil de pequenas gotículas de fala e sua importância potencial na transmissão do SARS-CoV-2. Proc Natl Acad Sci U. S A. 117(22):1187511877. Junho, 2020.

9- Gandolfi MG. et al. Risks of Aerosol Contamination in Dental Procedures during the Second Wave of COVID-19-Experience and Proposals of Innovative IPC in Dental Practice. Int J Environ Res Public Health. 1;17(23):8954. Dezembro, 2020. 
10- Castro MS, Castilho AVSS, Azevedo-Silva LJ, Santos LF, Orenha ES, Sales-Peres SHC "Coronavirus Disease 2019 Biological Risk and Clinical Care Protocol in Dentistry: A Systematic Review". Acta Scientific Dental Sciences 5.5 (2021): 28-43.

11-ORNELL, F. et al. "Pandemic fear" and COVID-19: mental health burden and strategies. Braz. J. Psychiatry, São Paulo, 2020

12-Maunder, R.; Lancee, W.; Rourke, S.; Hunter, J.; Goldbloom, D.; Balderson, K.; Petryshen, P.; Steinberg, R.; Wasylenki, D.; Koh, D.; et al. Factors Associated with the Psychological Impact of Severe Acute Respiratory Syndrome on Nurses and Other Hospital Workers in Toronto. Psychosom. Med. 2004, 66, 938-942.

13-Emary KRW, Golubchik T, Aley PK, Ariani CV, Angus B, Bibi S, et al. COVID-19 Genomics UK consortium; AMPHEUS Project; Oxford COVID-19 Vaccine Trial Group. Efficacy of ChAdOx1 nCoV-19 (AZD1222) vaccine against SARS-CoV-2 variant of concern 202012/01 (B.1.1.7): an exploratory analysis of a randomised controlled trial. Lancet. 2021 Apr 10;397(10282):1351-1362. doi: 10.1016/S01406736(21)00628-0. Epub 2021 Mar 30. PMID: 33798499; PMCID: PMC8009612.

14- Chen J, Lu H. New challenges to fighting COVID-19: Virus variants, potential vaccines, and development of antivirals. Biosci Trends. 2021 Mar 19. doi: 10.5582/bst.2021.01092. Epub ahead of print. PMID: 33746183.

15- Vilela NB, Vidal SV. A equipe de enfermagem de um hospital e a Síndrome de Burnout: relação perigosa. Rev. pesqui. cuid. fundam. (Online). 2010; outubro/dezembro; 2(4):1275-1285.

16- Trindade LL, Lautert L. Síndrome de Burnout entre os trabalhadores da Estratégia de Saúde da Família. Rev. Esc. Enferm. USP. [Internet]. 2010; 44(2):274-9

17-Fessell D, Cherniss C. Coronavirus Disease 2019 (COVID-19) and Beyond: Micropractices for Burnout Prevention and Emotional Wellness. J. Am. Coll. Radiol. 2020, pii: S1546-1440(20)30290-8. doi: 10.1016/j.jacr.2020.03.013. 
18- Maslach C. Burnout: a multidimensional perspective. In: Schaufeli WB, Maslach C, Marek T, editors. Professional Burnout: Recent Developments in Theory and Research. Washington, DC: Taylor \& Francis; 1993

19-Demerouti E, Bakker AB, Vardakou I, Kantas A. The convergent validity of two Burnout instruments - A multitrait-multimethod analysis. European Journal of Psychological Assessment 2003; 19(1):12-23.

20- Campos JADB, Trotta OST, Bonafe FSS, Maroco J. Burnout em dentistas do serviço público: ter ou não ter, eis a questão! Rev Odontol UNESP. 2010; 39(2): 109-114.

21- Sguarezi, D. Avaliacao da Síndrome de Burnout em cirurgiões-dentistas no munícipio de Cuiabá, Estado do Mato Grosso, Brasil. 2014. 42 f. Dissertação- UNICAMP, Faculdade de Odontologia de Piracicaba, Piracicaba, SP. [Acesso em 26/01/2021] Disponívelem:http://www.repositorio.unicamp.br/handle/REPOSIP/28916 





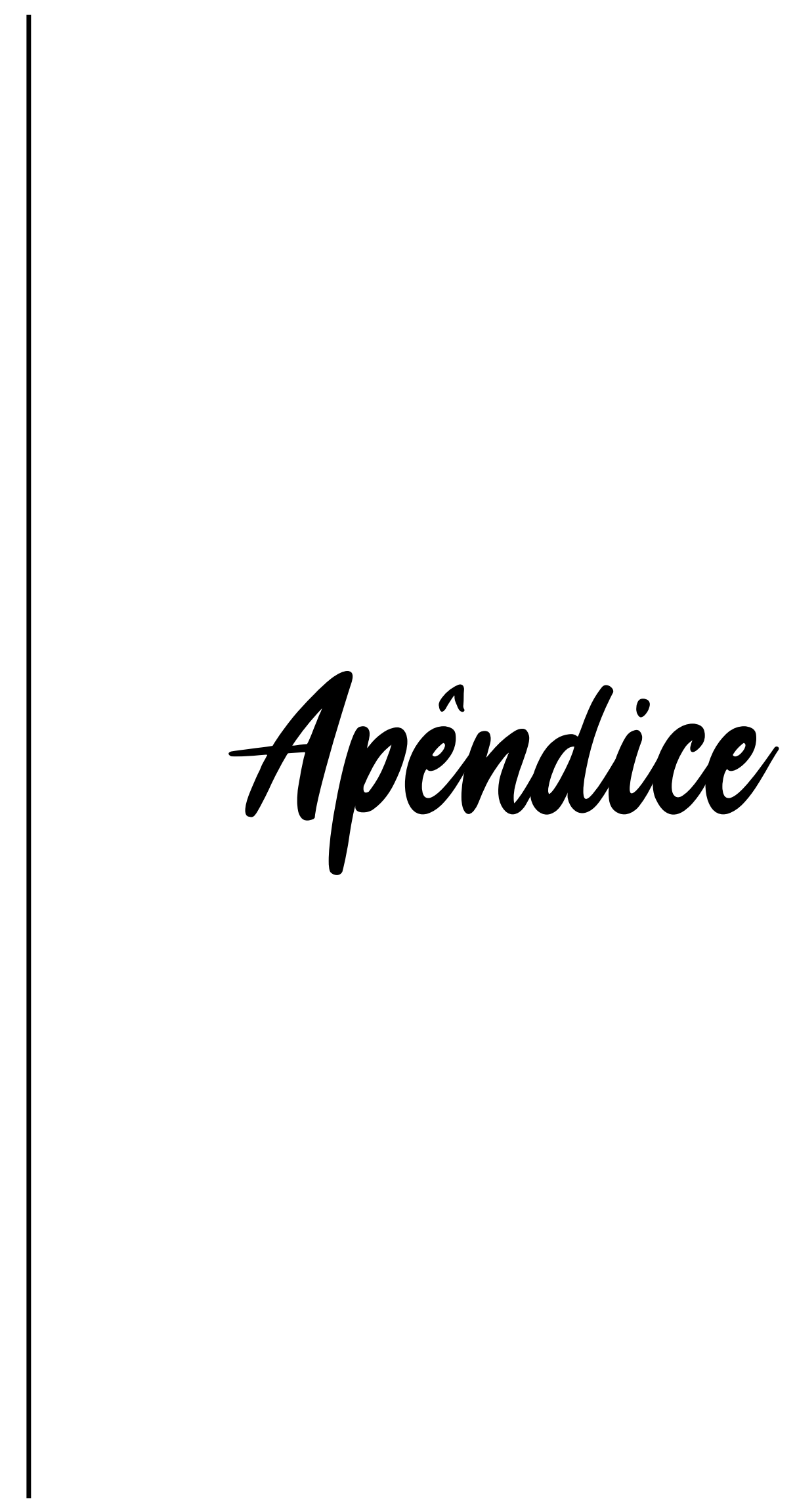







\section{APÊNCIDE A - DECLARAÇÃO DE USO EXCLUSIVO DE ARTIGO EM DISSERTAÇÃO}

\section{DECLARAÇÃO DE USO EXCLUSIVO DE ARTIGO EM DISSERTAÇÃO}

Declaramos estarmos cientes de que o trabalho "Impacto da pandemia de SARS-CoV-2 na saúde emocional e na Síndrome de Burnout em cirurgiões-dentistas no Brasil" será apresentado na Dissertação do aluno Marcelo Salmazo Castro e que não foi e nem será utilizado em outra dissertação dos Programas de Pós-Graduação da FOB-USP.

Bauru, 21 de setembro de 2021.

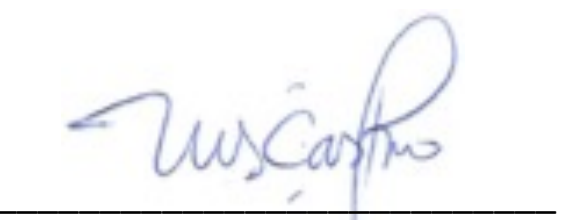

Marcelo Salmazo Castro

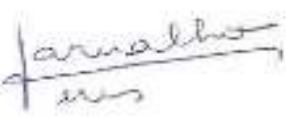

Silvia Helena de Carvalho Sales-Peres 





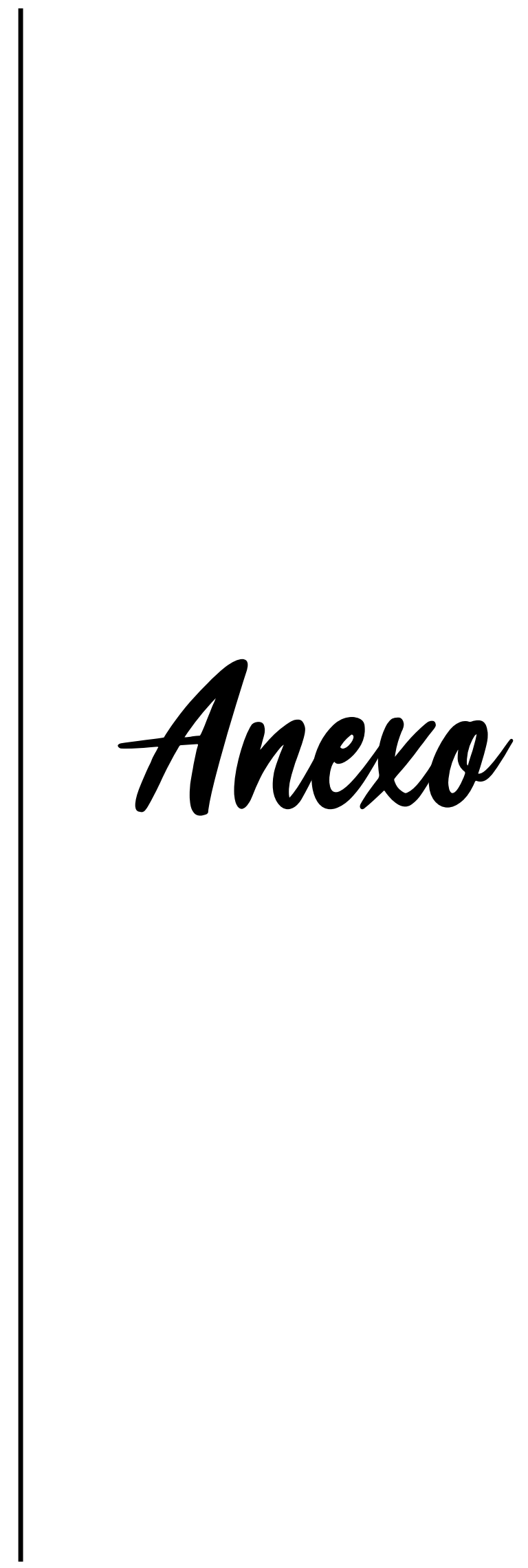







\section{ANEXO A - APROVAÇÃO PELO COMITÊ DE ÉTICA EM PESQUISA COM SERES HUMANOS - CEP}

\section{USP - FACULDADE DE ODONTOLOGIA DE BAURU DA USP}

\section{PARECER CONSUBSTANCIADO DO CEP}

\section{DADOS DO PROJETO DE PESQUISA}

Título da Pesquisa: Análise do impacto emocional causado pela pandemia de COVID-19 em dentistas brasileiros

Pesquisador: MARCELO SALMAZO CASTRO

Área Temática:

Versåo: 2

CAAE: 35177120.9 .0000 .5417

Instituiçăo Proponente: Universidade de Sao Paulo

Patrocinador Principal: Financiamento Próprio

\section{DADOS DO PARECER}

Número do Parecer: 4.239 .348

\section{Apresentaçăo do Projeto:}

O presente estudo será realizado com o objetivo de avaliar o impacto da pandemia do coronavirus-sars-cov2 na saúde mental de profissionais de odontologia, equipe de trabalho e em pacientes. A amostra deste estudo será composta por cirurgiōes-dentistas, inscritos regularmente no Conselho Federal de Odontologia do Brasil. Serăo enviados através de mídias sociais e emails, convites para os odontólogos participarem de uma pesquisa voluntaria e online, através de um link de formulário do Google Forms.

\section{Objetivo da Pesquisa:}

Avaliar o impacto na saúde mental causado pela pandemia do coronavirus 19 no odontólogo, sua equipe e pacientes.

\section{Avaliaçăo dos Riscos e Benefícios:}

De acordo com os pesquisadores, o participante voluntário terá que dispor de um tempo para responder o questionário, o que poderá gerar algum desconforto, cansaço ou constrangimento. Caso o voluntário se sentir constrangido com alguma pergunta do questionário, o participante poderá deixar de responder qualquer questăo que julgar pertinente, bem como poderá se recusar a participar ou desistir da pesquisa a qualquer momento sem que ocorra qualquer prejuízo ao

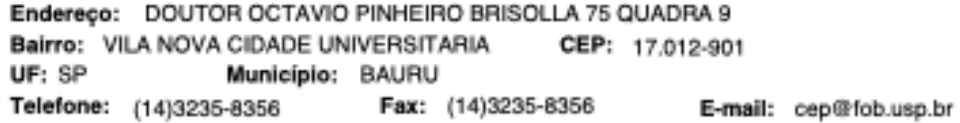




\section{USP - FACULDADE DE ODONTOLOGIA DE BAURU DA USP}

Continuaçso do Parecer: 4.239.348

voluntário. Há também o risco de exposiçăo dos dados, no entanto, os pesquisadores se comprometem a guardar sigilo das informaçŏes fornecidas pelo participante.

Como benefícios, após a conclusẵo da mesma, o participante terá acesso aos resultados e conclusőes do estudo, podendo verificar qual a conduta mais apropriada para utilizar na sua rotina diária de atendimento, podendo melhorar a sua rotina de biossegurança pessoal, a dinămica de trabalho e o seu rendimento profissional, trazendo benefícios também a seus colaboradores, familiares e pacientes.

\section{Comentários e Consideraçōes sobre a Pesquisa:}

Trata-se de versăo 2 para correçăo de pendências.

Consideraçōes sobre os Termos de apresentação obrigatória:

Estăo adequados. As pendências foram atendidas.

Recomendaçőes:

Năo se aplica.

Conclusōes ou Pendências e Lista de Inadequaçōes:

Projeto aprovado sem pende̊ncias de ordem ética.

\section{Consideraçôes Finais a critério do CEP:}

Esse projeto foi considerado APROVADO ad referendum deste CEP e seguindo orientaçŏes da CONEP, para análise de protocolos envolvendo COVID-19 e com base nas normas éticas da Resoluçăo CNS 466/12. Ao término da pesquisa o CEP-FOB/USP exige a apresentaçăo de relatório final. Os relatórios parciais deverăo estar de acordo com o cronograma e/ou parecer emitido pelo CEP. Alteraçŏes na metodologia, título, inclusăo ou exclusăo de autores, cronograma e quaisquer outras mudanças que sejam significativas deverăo ser previamente comunicadas a este CEP sob risco de năo aprovaçăo do relatório final. Quando da apresentaçăo deste, deverăo ser incluídos todos os TCLEs e/ou termos de doaçăo assinados e rubricados, se pertinentes.

Este parecer foi elaborado baseado nos documentos abaixo relacionados:

\begin{tabular}{|c|c|c|c|c|}
\hline Tipo Documento & Arquivo & Postagem & Autor & Situação \\
\hline $\begin{array}{l}\text { Informaçóes Básicas } \\
\text { do Projeto }\end{array}$ & \begin{tabular}{|l|} 
PB_INFORMAÇÓES_BÁSICAS_DO_P \\
RO.JETO 1592414.pdf
\end{tabular} & $\begin{array}{c}12 / 08 / 2020 \\
14: 56: 11\end{array}$ & & Aceito \\
\hline $\begin{array}{l}\text { Projeto Detalhado / } \\
\text { Brochura } \\
\text { Investigador }\end{array}$ & Projetoburnout2.pdf & $\begin{array}{c}12 / 08 / 2020 \\
14: 35: 22\end{array}$ & $\begin{array}{l}\text { MARCELO } \\
\text { SALMAZO CASTRO }\end{array}$ & Aceito \\
\hline
\end{tabular}

Endereço: DOUTOR OCTAVIO PINHEIRO BAISOLLA 75 QUADRA 9

Bairro: VILA NOVA CIDADE UNIVERSITARIA CEP: $17.012-901$

UF: SP Municipio: BAUAU

Telefone: (14)3235-8356 Fax: (14)3235-8356 E-mail: ceperfob.usp.br 


\section{USP - FACULDADE DE ODONTOLOGIA DE BAURU DA USP}

Continuaçso do Pareoer: 4.239.348

\begin{tabular}{|c|c|c|c|c|}
\hline Parecer Anterior & ParecerCEP1.pdf & $\begin{array}{c}12 / 08 / 2020 \\
14: 33: 05 \\
\end{array}$ & \begin{tabular}{|l|} 
MARCELO \\
SALMAZO CASTRO
\end{tabular} & Aceito \\
\hline $\begin{array}{l}\text { Solicitaçăo Assinada } \\
\text { pelo Pesquisador } \\
\text { Responsável }\end{array}$ & OficioencaminhamentoCEP.pdf & $\begin{array}{c}12 / 08 / 2020 \\
14: 31: 54\end{array}$ & $\begin{array}{l}\text { MARCELO } \\
\text { SALMAZO CASTRO }\end{array}$ & Aceito \\
\hline $\begin{array}{l}\text { TCLE / Termos de } \\
\text { Assentimento / } \\
\text { Justificativa de } \\
\text { Ausência }\end{array}$ & TCLEPsicologico2.pdf & $\begin{array}{c}12 / 08 / 2020 \\
14: 30: 58\end{array}$ & $\begin{array}{l}\text { MARCELO } \\
\text { SALMAZO CASTRO }\end{array}$ & Aceito \\
\hline Outros & ChecklistCEP.pdf & $\begin{array}{c}15 / 07 / 2020 \\
10: 39: 57 \\
\end{array}$ & $\begin{array}{l}\text { MARCELO } \\
\text { SALMAZO CASTRO }\end{array}$ & Aceito \\
\hline $\begin{array}{l}\text { Declaraçăo de } \\
\text { Instituiçắo e } \\
\text { Infraestrutura }\end{array}$ & Termodeaquiescencia.pdf & $\begin{array}{c}15 / 07 / 2020 \\
10: 38: 40\end{array}$ & $\begin{array}{l}\text { MARCELO } \\
\text { SALMAZO CASTRO }\end{array}$ & Aceito \\
\hline $\begin{array}{l}\text { Declaraçăo de } \\
\text { Pesquisadores }\end{array}$ & $\begin{array}{l}\text { DeclaracaoCompromissoPesquisadorRe } \\
\text { sultadosPesquisa.pdf }\end{array}$ & $\begin{array}{c}15 / 07 / 2020 \\
10: 35: 37 \\
\end{array}$ & $\begin{array}{l}\text { MARCELO } \\
\text { SALMAZO CASTRO }\end{array}$ & Aceito \\
\hline Folha de Rosto & folhaderostomarcelo.pdf & $\begin{array}{c}15 / 07 / 2020 \\
10: 35: 06\end{array}$ & $\begin{array}{l}\text { MARCELO } \\
\text { SALMAZO CASTRO }\end{array}$ & Aceito \\
\hline
\end{tabular}

Situação do Parecer:

Aprovado

Necessita Apreciaçăo da CONEP:

Nằ

BAURU, 26 de Agosto de 2020

\section{Assinado por:}

Juliana Fraga Soares Bombonatti

(Coordenador(a))

Endereço: DOUTOR OCTAVIO PINHEIRO BAISOLLA 75 QUADRA 9

Bairro: VILA NOVA CIDADE UNIVERSITARIA CEP: 17.012-901

UF: SP Municipio: BAURU

Telefone: (14)3235-8356 Fax: (14)3235-8356 E-mail: cep 
ANEXO B - TERMO DE CONSENTIMENTO LIVRE ESCLARECIDO

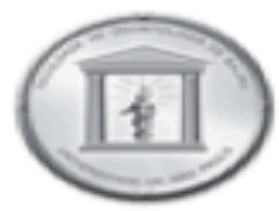

\author{
Universidade de São Paulo \\ Faculdade de Odontologia de Bauru \\ Departamento de Odontopediatria, Ortodontia e Saúde Coletiva \\ Áea Departamental de Sabde Colativa
}

\title{
Termo de Consentimento Livre e Esclarecido
}

Gostariamos de convidá-lo a participar da pesquisa "Análise do impacto emocional causado pela pandemia de COVID-19 em dentistas brasileiros", de autoria e responsabilidade de Marcelo Salmazo Castro e Silvia Helena de Carvalho Sales Peres, a ser realizada na Faculdade de Odontologia de Bauru - Universidade de São Paulo, Bauru, São Paulo. No ano de 2020, uma nova cepa viral do Corona virus (Sars-Cov-2), foi inicialmente observada entre as pessoas residentes em Wuhan, província de Hubei, na China e de lá se propagou rapidamente pelos diferentes continentes. Em 11 de março de 2020 a Organização Mundial da Saúde declarou estado de Pandemia pela elevação de contaminação da infecção causado pelo COVID-19. O presente estudo terá como objetivo, através de um estudo transversal, avaliar o impacto na saúde mental causado pela pandemia do coronavirus 19 no odontólogo, sua equipe e pacientes. A coleta de dados desta pesquisa está prevista para ocorrer em setembro/2020. A participação nesta pesquisa é totalmente voluntária e o Sr. poderá se recusar a participar ou desistir da pesquisa a qualquer momento sem ocorrer qualquer prejuizo. É importante ressaltar que o participante nāo será remunerado e nāo terá gasto especifico relacionado a pesquisa. É importante destacar que os dados dos participantes serão sigilosos, sendo manipulados somente pelos responsáveis da pesquisa, assegurando proteçăo de sua imagem e respeitando valores morais, culturais, religiosos, éticos e sociais. Os futuros resultados da pesquisa poderäo ser publicados e, mesmo assim, sua identidade será preservada. O participante voluntário terá que dispor de um tempo para responder o questionário, o que poderá gerar algum desconforto, cansaço ou constrangimento. Caso o voluntário se sentir constrangido com alguma pergunta do questionário, o participante poderá deixar de responder qualquer questäo que julgar pertinente, bem como poderá se recusar a participar ou desistir da pesquisa a qualquer momento sem que ocorra qualquer prejuizo ao voluntário. Há também o risco de exposição dos dados, no entanto, os pesquisadores se comprometem a guardar sigilo das informaçōes fornecidas pelo participante. O participante voluntário será beneficiado com esta pesquisa, visto que, após a conclusão da mesma, ele terá acesso aos resultados e conclusōes do estudo, podendo verificar qual a conduta mais apropriada para utilizar na sua rotina diária de atendimento, podendo melhorar a sua rotina de biossegurança pessoal, a dinâmica de trabalho e o seu rendimento profissional, trazendo beneficios também a seus colaboradores, familiares e pacientes. O senhor terá garantia de indenização diante de eventuais danos decorrentes da pesquisa, de acordo com a Resoluçäo CNS no 466 de 2012. A amostra do presente estudo será composta por cirurgiōes-dentistas regularmente registrados nos Conselhos Regionais de Odontologia do seu estado de residência. A sua participação é muito importante, pois, se este estudo atingir a profundidade desejada, obteremos dados e conclusōes a respeito do impacto psicológico causado no odontólogo devido aos riscos de contaminaçāo do Covid19. Todo participante poderá fazer o download através de um link postado junto ao formulário e imprimir uma cópia deste documento (TERMO DE CONSENTIMENTO LIVRE E ESCLARECIDO) que será assinado virtualmente e poderá ter acesso ao resultado ao final da pesquisa caso assim deseje. Também é garantido, se desejar, retirar-se da pesquisa a qualquer momento, sem que haja prejuizo pessoal. Para esclarecimento de dúvidas sobre sua participaçāo na pesquisa, o senhor poderá entrar em 
contato com o pesquisador no endereço: Alameda Dr. Octávio Pinheiro Brizolla 9-75 - Bauru SP, pelo telefone (14) 3235-8256 ou pelo e-mail: marcelocastro@usp.br . Para denúncias e ou reclamaçōes, entrar em contato com o Comitê de Ética em Pesquisa FOB-USP: Alameda Dr. Octávio Pinheiro Brizolla 9-75 - Bauru-SP ou pelo telefone (14) 3235-8356, email: cep@fob.usp.br, quando pertinente. Pelo presente instrumento que atende as exigências legais, após leitura minuciosa das informaçōes constantes neste TERMO DE CONSENTIMENTO LIVRE E ESCLARECIDO, não restando quaisquer dúvidas a respeito do lido, DECLARA E FIRMA seu CONSENTIMENTO LIVRE E ESCLARECIDO concordando em participar da pesquisa proposta. Fica claro que o participante da pesquisa, pode a qualquer momento retirar seu CONSENTIMENTO LIVRE E ESCLARECIDO e deixar de participar desta pesquisa e ciente de que todos resultados obtidos com a coleta de dados e exame clínico tornar-se-āo confidenciais e guardados por força de sigilo profissional (Art 9o do Código de Ética Odontológica).

Por fim, como pesquisador responsável pela pesquisa, DECLARO o cumprimento do disposto na Resoluçāo CNS no 466 de 2012, contidos nos itens IV.3, item IV.5-a e na integra com a resolução CNS no 466 de dezembro de 2012.

O Comitê de Ética em Pesquisa - CEP, organizado e criado pela FOB-USP, em 29/06/1998 (Portaria GD/0698/FOB), previsto no item VII da Resolução $n^{\circ} 466 / 12$ do Conselho Nacional de Saúde do Ministério da Saúde (publicada no DOU de 13/06/2013), é um Colegiado interdisciplinar e independente, de relevância pública, de caráter consultivo, deliberativo educativo, criado para defender os interesses dos participantes da pesquisa em sua integridade e dignidade e para contribuir no desenvolvimento da pesquisa dentro de padrōes éticos.

Qualquer denúncia e/ou reclamação sobre sua participaçāo na pesquisa poderá ser reportada a este CEP:

Horário e local de funcionamento:

Comitê de Ética em Pesquisa

Faculdade de Odontologia de Bauru-USP - Prédio da Pós-Graduação (bloco E - pavimento superior), de segunda à sexta-feira, no horário das $13 \mathrm{~h} 30$ às 17 horas, em dias úteis.

Alameda Dr. Octávio Pinheiro Brisolla, 9-75 
DECLARO QUE LI E FIRMO MEU TERMO DE CONSENTIMENTO LIVRE E ESCLARECIDO, concordando em participar de forma voluntária da pesquisa proposta.

Sim

Nä̀

Como particlpante de uma pesquisa online, você pode imprimir este TCLE eletrônico acessando-o pelo link:

https://drive.google.com/file/d/1QmuMGdln83aVgXSs3WJX08I1TOIQCREk/view? usp=sharing 
ANEXO C - QUESTIONÁRIO AVALIATIVO

Aspectos Demográficos de formação e atuação profissional

Em qual estado brasileiro você atua profissionalmente? *

Escolher

Sexo ?*

Escolher

Cldade de atuação? *

Sua resposta

Qual a sua falxa etária? *

Entre 20 e 30 anos

Entre 31 e 40 anos

Entre 41 e 50 anos

Entre 51 e 60 anos

Mais de 61 anos

Vc se graduou em uma instituição? *

Pública

Privada 
Há quantos anos vocé está graduado? *

Entre 0 e 5 anos

Entre 6 e 10 anos

Entre 11 e 15 anos

Entre 16 e 20 anos

Entre 21 e 25 anos

Entre 26 e 30 anos

Mais de 30 anos

Qual a sua atuaçẫo clínica? *

Clínico geral

Especialista

Você atua em qual setor de atividade? *

Privado

Público

Ambos

Qual a sua carga de trabalho semanal? *

De 1 à 10 horas

De 11 à 20 horas

De 21 à 30 horas

De 31 à 40 horas

De 41 à 50 horas

Mais de 50 horas 
Avaliaçẫo dos conhecimentos e receios profissionais relacionados ao tratamento odontológico durante a Pandemia

Vocé está adiando o tratamento de pacientes que apresentem sintomas suspeitos de COVID19?*

Sim

Nấo

Você tem medo de ser infectado com o COVID-19 durante a realização de um procedimento odontológico? *

Sim

Nลี่

Vocẻ suspendeu todos os atendimentos da sua clínica odontológica até o controle da Pandemia? *

Sim

Nấ

Suspendi temporariamente, porém já retornei aos atendimentos.

Vocé NÃO está realizando algum tipo de atendimento em sua clínica odontológica por o considerar mais invasivo e portanto, mals susceptivel a uma possivel contaminaçẩo? *

Sim

Nấo

Com a instalação da pandemia de COVID-19 você pretende? *

Seguir na profissăo trabalhando da mesma maneira, apenas redobrando os cuidados de biossegurança

Diminuir a jornada de trabalho

Trabalhar somente com atividades não invasivas

Buscar outras alternativas dentro da carreira odontológica

Deixar a profissẫo 
Com a instalação da pandemia de COVID-19 você pretende? *

Seguir na profissāo trabalhando da mesma maneira, apenas redobrando os cuidados de biossegurança

Diminuir a jornada de trabalho

Trabalhar somente com atividades não invasivas

Buscar outras alternativas dentro da carreira odontológica

Deixar a profissão

Vocè tem medo de se contaminar durante o seu trabalho e transmiti-la para a sua familia? *

Sim

Nä́o

Vocẻ sente medo quando ouve que as pessoas estão morrendo por causa do COVID-19? *

Sim

Não

As vezes

Vocẻ conhece algum odontólogo que tenha testado positivo para o COVID-19? *

Sim

Nẫo

Vocé já atendeu algum paciente que tenha testado positivo ao COVD19 ?*

Sim

NẼo

Talvez 
Vocẻ ou algum membro da sua equipe já testaram positivo ao COVID19 ?*

Sim

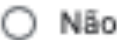

Você está com medo de realizar algum atendimento clínico em outros profissionals de saúde? *

Sim

NËo

Talvez

Você acha que possui conhecimentos suficientes das medidas protetivas a contaminaçăo do COVD19? *

Sim

Naio

Talvez 
Avaliação de Burnout

Sindrome de Burnout ou Sindrome do Esgotamento Profissional é um distúrbio emocional com sintomas de exaustâo extrema, estresse e esgotamento físico resultante de situaçóes de trabalho desgastante, que demandam muita competitividade ou responsabilidade.

A principal causa da doença é justamente o excesso de trabalho. Esta síndrome é comum em prófissionais que atuam diariamente sob

pressấo e com responsabilidades constantes, como médicos,

enfermeiros, professores, policiais, odontólogos, dentre outros.

Há dias em que me sinto cansado ainda antes mesmo de chegar ao trabalho*

Discordo completamente

Discordo

Concordo

Concordo completamente

Depols do trabalho, preciso de mais tempo para relaxar e sentir-me melhor do que precisava antigamente *

Discordo completamente

Discordo

Concordo

Concordo completamente

Consigo suportar muito bem as pressōes do meu trabalho *

Discordo completamente

Discordo

Concordo

Concordo completamente

Durante o meu trabalho, sinto-me emocionalmente esgotado *

Discordo completamente

Discordo

Concordo

Concordo completamente 
Depois das tarefas profissionais, tenho geralmente energia para as minhas atividades de lazer *

Discordo completamente

Discordo

Concordo

Concordo completamente

Quando trabalho, sinto-me geralmente com energla *

Discordo completamente

Discordo

Concordo

Concordo completamente

Depols do meu trabalho, sinto-me cansado e sem energia *

Discordo completamente

Discordo

Concordo

Concordo completamente

De uma forma geral, consigo administrar bem a quantidade de trabalho que tenho *

Discordo completamente

Discordo

Concordo

Concordo completamente

Encontro com frequência casos novos e interessantes no meu trabalho $*$

Discordo completamente

Discordo

Concordo

Concordo completamente 
Encontro com frequência casos novos e interessantes no meu trabalho $*$

Discordo completamente

Discordo

Concordo

Concordo completamente

Cada vez falo mais e com mais frequência de forma negativa sobre meu trabalho *

Discordo completamente

Discordo

Concordo

Concordo completamente

Ultimamente, tenho pensado menos no meu trabalho e o realizo de forma quase mecânica *

Discordo completamente

Discordo

Concordo

Concordo completamente

Considero que meu trabalho é um desafio positivo *

Discordo completamente

Discordo

Concordo

Concordo completamente 
Com o passar do tempo, sinto-me desligado do meu trabalho *

Discordo completamente

Discordo

Concordo

Concordo completamente

Este è o único tipo de trabalho que me imagino fazendo *

Discordo completamente

Discordo

Concordo

Concordo completamente

Sinto-me cada vez mais empenhado no meu trabalho *

Discordo completamente

Discordo

Concordo

Concordo completamente

As vezes, sinto-me farto das minhas tarefas *

Discordo completamente

Discordo

Concordo

Concordo completamente 